\title{
Capillary Electrophoresis for Measuring Biological Interactions: Binding Affinity and Enzyme Kinetics
}

\author{
Ted Langan \\ West Virginia University
}

Follow this and additional works at: https://researchrepository.wvu.edu/etd

\section{Recommended Citation}

Langan, Ted, "Capillary Electrophoresis for Measuring Biological Interactions: Binding Affinity and Enzyme Kinetics" (2012). Graduate Theses, Dissertations, and Problem Reports. 3587.

https://researchrepository.wvu.edu/etd/3587

This Dissertation is protected by copyright and/or related rights. It has been brought to you by the The Research Repository @ WVU with permission from the rights-holder(s). You are free to use this Dissertation in any way that is permitted by the copyright and related rights legislation that applies to your use. For other uses you must obtain permission from the rights-holder(s) directly, unless additional rights are indicated by a Creative Commons license in the record and/ or on the work itself. This Dissertation has been accepted for inclusion in WVU Graduate Theses, Dissertations, and Problem Reports collection by an authorized administrator of The Research Repository @ WVU.

For more information, please contact researchrepository@mail.wvu.edu. 


\title{
Capillary Electrophoresis for Measuring
}

\section{Biological Interactions:}

\section{Binding Affinity and Enzyme Kinetics}

\author{
By \\ Ted Langan \\ Dissertation submitted to the Eberly College of Arts and Sciences \\ at West Virginia University \\ in partial fulfillment of the requirements \\ for the degree of \\ Doctor of Philosophy \\ in \\ Chemistry \\ Approved by \\ Lisa Holland, Ph.D., Committee Chairperson \\ Fred King, Ph.D. \\ Ronald Smart, Ph.D. \\ Björn Söderberg, Ph.D. \\ Michelle Richards-Babb, Ph.D. \\ Patrick Callery, Ph.D. \\ C. Eugene Bennett Department of Chemistry \\ Morgantown, West Virginia \\ 2012
}

Keywords: capillary electrophoresis, electrospray, aptamer, steroids, oligosaccharides, phospholipids

Copyright (C) 2012 Ted Langan 


\author{
Abstract \\ Capillary Electrophoresis for Measuring \\ Biological Interactions: \\ Binding Affinity and Enzyme Kinetics \\ By Ted Langan
}

This dissertation is based upon research in the use of capillary electrophoresis for the measurement of biological interactions. The studies presented here research two classes of analytes, steroids and oligosaccharides, both of which have profound importance to biological systems. Capillary electrophoresis separation methods were utilized to determine binding affinity and enzyme kinetic constants. The second chapter describes the first use of a semi-permanent phospholipid coating that is utilized in capillary electrophoresis-electrospray ionization-mass spectrometry (CE-ESI-MS) for the purpose of monitoring enzymatic hydrolysis and the detection of maltooligosaccharides. Although phospholipids in free solution are generally unused in ESI, they did not interfere with the detection of linear and branched oligosaccharides using ESI operated in negative mode. The CE and ESI were coupled using a coaxial sheath flow interface. The separation was operated in reversed polarity, and the electroosmotic flow was effectively suppressed by the phospholipid coating. The method was characterized with linear oligosaccharides and used to monitor the enzymatic hydrolysis of maltooligosaccharides with $\alpha$-amyloglucosidase. Branched oligosaccharides were separated and detected with the system. The enzyme $\beta 1-4$ galactosidase was used to distinguish branched isomeric oligosaccharides derived from asialofetuin. The third chapter of this dissertation presents 
the measurement of the binding affinity of $17 \beta$-estradiol with an immobilized DNA aptamer by using capillary electrophoresis. Estradiol captured by the immobilized aptamer was injected into the separation capillary using $\mathrm{pH}$-mediated sample stacking. Stacked $17 \beta$-estradiol was then separated using micellar electrokinetic capillary chromatography and detected with UV-visible absorbance. Following incubation with immobilized DNA, analysis of free and bound estradiol yielded a dissociation constant of $70 \pm 10 \mu \mathrm{M}$. The method was also used to screen binding affinity of the aptamer for other steroids. Chapter three demonstrates the effectiveness of capillary electrophoresis to assess the binding affinity of DNA aptamers. 


\section{Dedication}

This research is dedicated to my grandmother, Corlista (Pat) Murphy Crowe, who instilled the need to do things in the best possible way, to be honest, to persevere, and to advance my education. She has dedicated her life to learning, working hard, and teaching others.

My work has been completed with the constant support and love of my family: James, Bonnie, Cora, and Alysa Langan. 


\section{Acknowledgment}

A special gratitude to Dr. Lisa Holland who supported, guided, and structured my research throughout my experience in analytical chemistry at West Virginia University.

Thanks to the committee members from West Virginia University: Dr. Lisa Holland, Dr. Fred King, Dr. Ronald Smart, Dr. Björn Söderberg, Dr. Michelle RichardsBabb, and Dr. Patrick Callery for their advice, instruction, and time.

Appreciation is extended to the faculty and staff at the Department of Chemistry at WVU for the advancement of scientific knowledge through courses, seminars, and teaching.

Thank you to electrician, Phillip Tucker, for the assistance with custom designed scientific equipment. Also, thanks to Allen Burns, Donald Feathers, and Randall Eaglen for aiding in the construction of the custom built instrumentation and for helping repair and maintain the laboratory equipment.

Appreciation is given to the members of the Timperman laboratory: Dr. Aaron Timperman and Brent \& Kathleen Reschke for instruction on fabrication and development of microfluidic devices.

A special gratitude to my fellow group members of the Holland laboratory: Dr. Theron Pappas, Dr. Liliya Bykova, Dr. Ruijian Luo, Dr. Stephanie Archer-Hartmann, Dr. Christian White, Xingwei Wu, Vincent Nyakubaya, and Brandon Durney for their teamwork, support, and friendship during my years of study at West Virginia University. 


\section{Table of Contents}

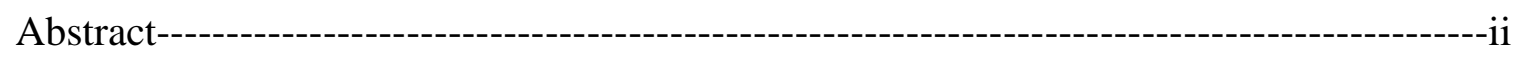

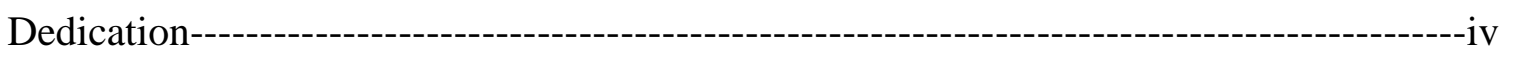

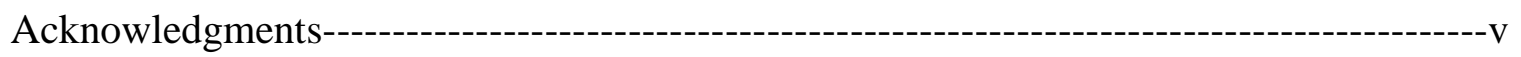

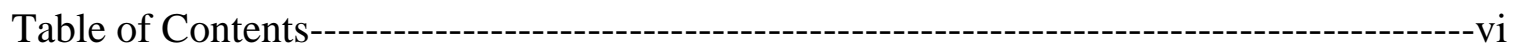

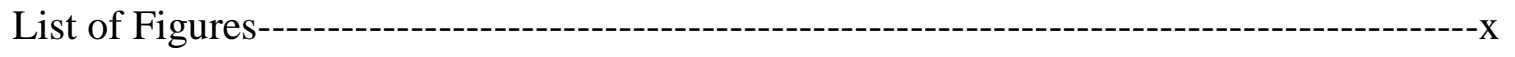

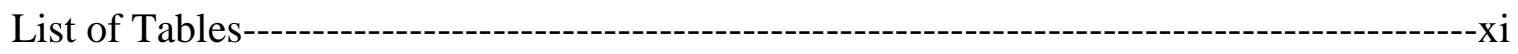

List of Symbols and Nomenclature----------------------------------------------------------------Xii

Chapter 1: Introduction to Capillary Electrophoresis, Binding Affinity, and Enzyme

Kinetics----------------------------------------------------------------------------------------------------------1

1.1 Capillary Electrophoresis------------------------------------------------------------------2

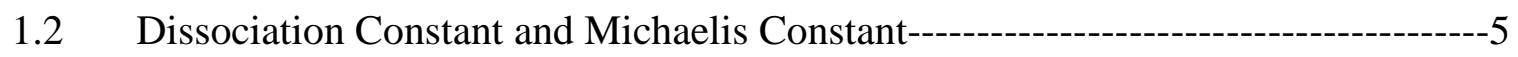

1.2.1 Calculation for Predicting the One-to-One Binding Curve with Excel-----5

1.2.2 Conventional Calculation of $\mathrm{K}_{\mathrm{d}}$ from Experimental Results-----------------11

1.2.3 Conventional Calculation of $\mathrm{K}_{\mathrm{M}}$ from Experimental Results----------------14

1.3 Challenges for Chemical Separations-----------------------------------------------------17

1.4 Bibliography------------------------------------------------------------------------------------19 
Chapter 2: Determination of Oligosaccharides Labeled with 1-Aminopyrene-3,6,8-

Trisulfonic Acid with Capillary Electrophoresis Coupled to Electrospray Through a

Coaxial Sheath Flow Interface with a Semi-Permanent Phospholipid Coating-------------20

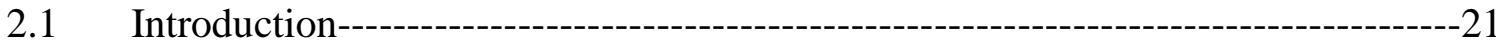

2.1.1 Basics of Electrospray Ionization-----------------------------------------------22

2.1.2 Coatings in Capillary Electrophoresis-------------------------------------------24

2.1.3 Coupling of Capillary Electrophoresis with Mass Spectrometry------------26

2.2 System Selection: Coaxial Sheath Flow-----------------------------------------------31

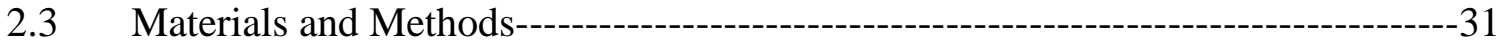

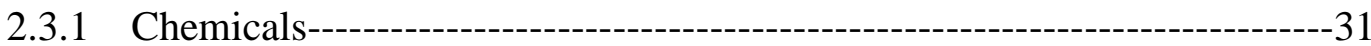

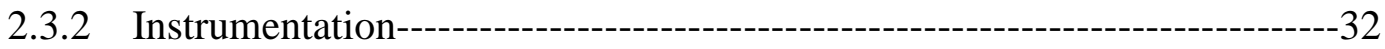

2.3.3 Capillary Preparation------------------------------------------------------------------35

2.3.4 Glycan Sample Preparation and Derivatization---------------------------------36

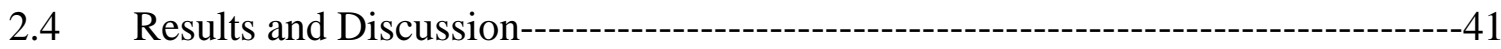

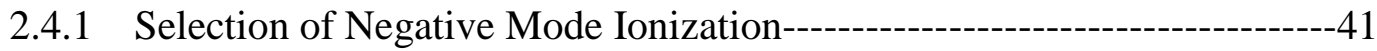

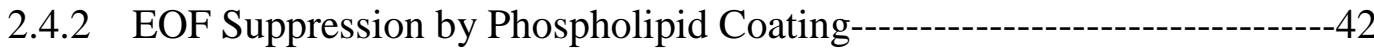

2.4.3 Selection of Running Electrolyte and Optimization of Flow Rate----------43

2.4.4 Application of Linear Maltooligosaccharides-----------------------------------44

2.4.5 Enzyme Hydrolysis of Linear Maltooligosaccharides------------------------48

2.4.6 Michaelis-Menten Analysis--------------------------------------------------------49

2.4.7 Fetuin Separations and Identification of Branched Oligosaccharides-----49

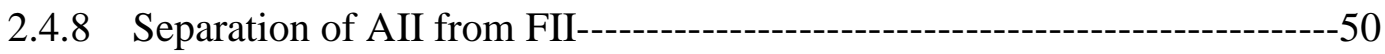

2.5 Conclusions----------------------------------------------------------------------------------------52 
2.6 Future Directions-----------------------------------------------------------------------------53

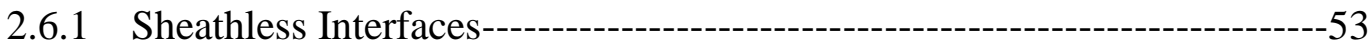

2.6.2 CE Fracture Capillary Interface---------------------------------------------------54

2.6.3 Microfluidic Chip Interfaces------------------------------------------------------56

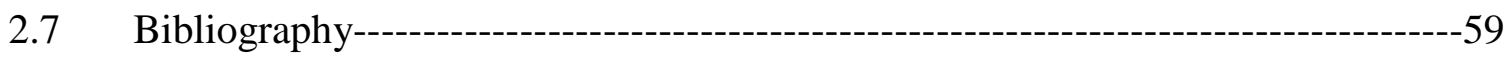

Chapter 3: Using pH-Mediated Sample Stacking with Micellar Electrokinetic Capillary Chromatography for the Assessment of Aptamer-Steroid Binding----------------------------63

3.1 Introduction---------------------------------------------------------------------------------64

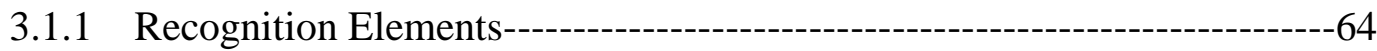

3.1.2 Aptamers---------------------------------------------------------------------------------65

3.1.3 Separation Mechanism---------------------------------------------------------------'67

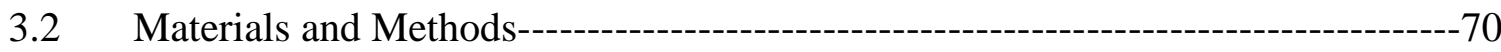

3.2.1 Chemicals---------------------------------------------------------------------------------70

3.2.2 Instrumentation-------------------------------------------------------------------------11

3.2.3 Capillary Electrophoresis--------------------------------------------------------------72

3.2.4 Sample Preparation--------------------------------------------------------------------72

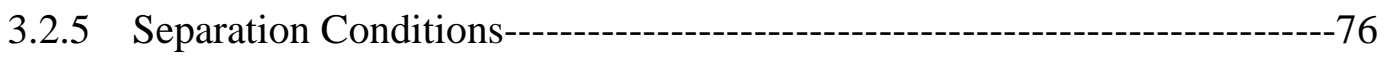

3.3 Results and Discussion------------------------------------------------------------------------77

3.3.1 Accounting for Nonspecific Binding---------------------------------------------77

3.3.2 Steroid Separations with Sample Stacking--------------------------------------78

3.3.3 Quantification with Standard Addition--------------------------------------------80 
3.3.4 Determination of $K_{d}$ by Nonlinear Regression with Nonspecific Binding and Variations in $\mathrm{B}_{\max }$------------------------------------------------------------82

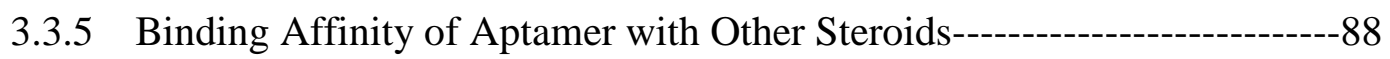

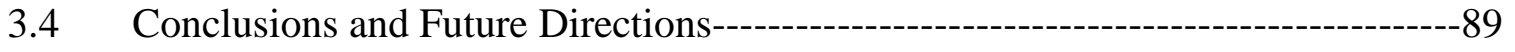

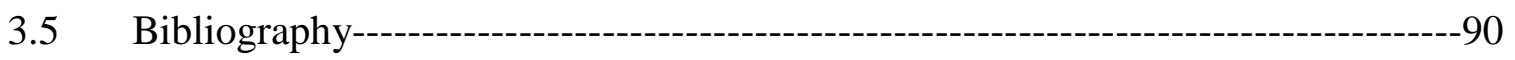

Curriculum Vitae------------------------------------------------------------------------------------------92 


\section{List of Figures}

Figure 1-1: Basic capillary electrophoresis----------------------------------------------------------4

Figure 1-2: Predicting the one-to-one binding with Excel sheet-------------------------------9

Figure 1-3: Predicting the one-to-one binding curve with Excel---------------------------10

Figure 1-4: Reaction plot of a generic enzyme-------------------------------------------------14

Figure 1-5: Typical Michaelis-Menten plot----------------------------------------------------16

Figure 2-1: Basic electrospray-------------------------------------------------------------------24

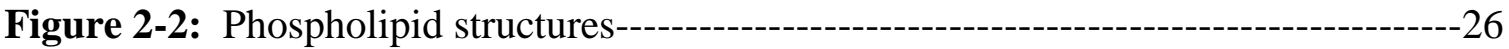

Figure 2-3: Coaxial sheath flow interface---------------------------------------------------28

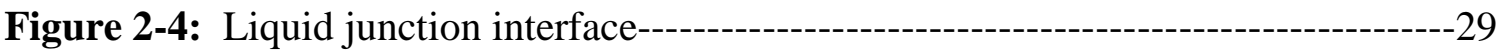

Figure 2-5: A schematic diagram of the custom-built CE system and ESI interface-----34

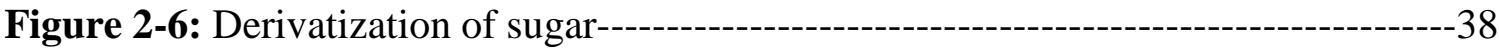

Figure 2-7: $\mathrm{pH}=7.0$ separations of enzymatic digest of maltoheptaose with $\alpha$ -

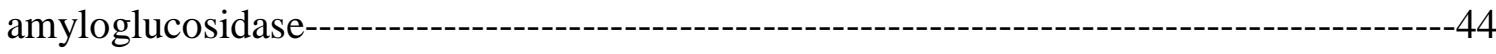

Figure 2-8: The general structure and the electrophoretic separation of APTS-labeled

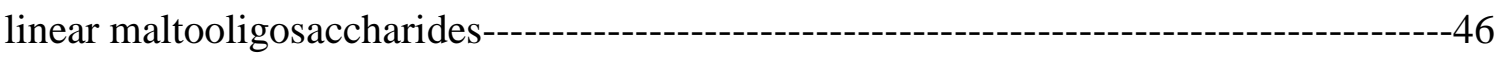

Figure 2-9: The enzymatic digest of maltoheptaose with $\alpha$-amyloglucosidase-------------48

Figure 2-10: Electropherogram of the AII/FII pair of branched isomeric

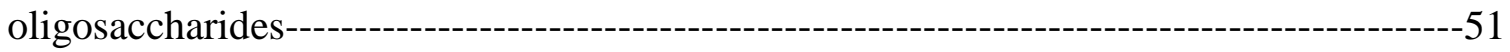

Figure 2-11: Fracture capillary sheathless interface------------------------------------------55

Figure 2-12: Simple double T microfluidic chip----------------------------------------------57 
Figure 2-13: Microfluidic chip with integrated hydrodynamic restrictor and nanospray

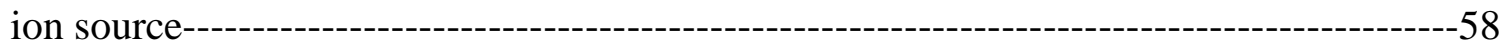

Figure 3-1: Separation mechanism-----------------------------------------------------------------69

Figure 3-2: Beckman Coulter P/ACE MDQ capillary electrophoresis instrument-------71 Figure 3-3: Overview of the method used to measure the dissociation constant of DNA

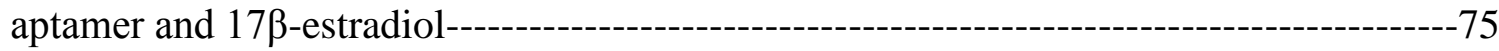

Figure 3-4: Typical electrophoretic separations for binding experiments------------------79

Figure 3-5: The electrophoretic separations following a single standard addition

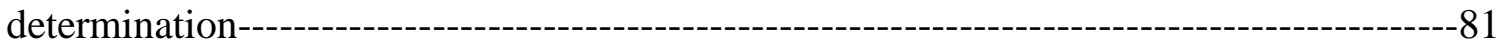

Figure 3-6: Two determinations of binding affinity of DNA aptamer and steroids------86

\section{List of Tables}

Table 2-1: Figures of Merit Obtained with Linear Oligosaccharides-----------------------47

Table 3-1: Raw Data Used for each Binding Isotherm----------------------------------------87 


\section{List of Symbols and Nomenclature}

[E] - enzyme concentration

[P] - product of concentration

[S] - substrate concentration

${ }^{\circ} \mathrm{C}$ - degrees Celsius

A - adenine

ACE - affinity capillary electrophoresis

APTS - 1-aminopyrene-3,6,8-trisulfonic acid

BGE - background electrolyte

$\mathrm{B}_{\max }$ - maximum binding of receptor

C - cytosine

CAPS - 3-[cyclohexylamino]-1-propanesulfonic acid

CE - capillary electrophoresis

CGE - capillary gel electrophoresis

CIEF - capillary isoelectric focusing

$\mathrm{cm}$ - centimeter; 1 x $10^{-2} \mathrm{~m}$

CMCD - carboxymethyl- $\beta$-cyclodextrin

CZE - capillary zone electrophoresis

$d[\mathrm{P}] / d \mathrm{t}$ - change in product of concentration per change in time

Da - dalton

DHPC - 1,2-Dihexanoyl-sn-Glycero-3-Phosphocholine

DMPC - 1,2-Dimyristoyl-sn-Glycero-3-Phosphocholine 
DNA - deoxyribonucleic acid

E1 - estrone

E2 - 17ß-estradiol

EE - 17 $\alpha$-ethynyl estradiol

EOF - electroosmotic flow

ESI - electrospray

$G$ - units of gravity

G - guanine

HPCD - hydroxypropyl- $\beta$-cyclodextrin

HV - high voltage

i.d. - inner diameter

$\mathrm{k}$ - rate constant

$\mathrm{K}_{\mathrm{d}}$ - dissociation constant

kDa - kilodalton; 1 x $10^{3} \mathrm{Da}$

$\mathrm{K}_{\mathrm{M}}$ - Michaelis constant

kPa - kilopascal; 1 x $10^{3} \mathrm{~Pa}$

$\mathrm{kV}$ - kilovolts; $1 \times 10^{3} \mathrm{~V}$

L - ligand

LOD - limit of detection

M - molar

$\mathrm{m} / \mathrm{z}$ - mass-to-charge

MEKC - micellar electrokinetic chromatography

mg - milligram; 1 x $10^{-3} \mathrm{~g}$ 


$$
\begin{aligned}
& \text { min - minutes } \\
& \mathrm{mL} \text { - milliliter; } 1 \times 10^{-3} \mathrm{~L} \\
& \text { mLOD - mass limit of detection } \\
& \mathrm{mM} \text { - millimolar; } 1 \text { x } 10^{-3} \mathrm{M} \\
& \text { MOPS - 3-(N-morpholino)propanesulfonic acid } \\
& \text { MS - mass spectrometry } \\
& \mathrm{M} \Omega \text { - megaohm; } 1 \times 10^{6} \Omega \\
& \mu \mathrm{A} \text { - microamp; } 1 \times 10^{-6} \mathrm{~A} \\
& \mu_{\mathrm{ap}} \text { - apparent mobility } \\
& \mu_{\text {ep }} \text { - electrophoretic mobility } \\
& \mu_{\text {eof }} \text { - electroosmotic mobility } \\
& \mu \mathrm{g} \text { - microgram; } 1 \text { × } 10^{-6} \mathrm{~g} \\
& \mu \mathrm{L} \text { - microliter; } 1 \times 10^{-6} \mathrm{~L} \\
& \mu \mathrm{m} \text { - micrometer; } 1 \times 10^{-6} \mathrm{~m} \\
& \mu \mathrm{M} \text { - micromolar; } 1 \times 10^{-6} \mathrm{M} \\
& \mathrm{nL} \text { - nanoliter; } 1 \times 10^{-9} \mathrm{~L} \\
& \mathrm{~nm} \text { - nanometer; } 1 \text { × } 10^{-9} \mathrm{~m} \\
& \text { NS - slope of nonspecific binding plot } \\
& \text { NSB - nonspecific binding } \\
& \text { PCR - polymerase chain reaction } \\
& \text { PDA - photodiode array } \\
& \text { psi - pounds per square inch } \\
& q \text { - charge }
\end{aligned}
$$


$r$ - hydrodynamic radius

$\mathrm{R}$ - receptor

$\mathrm{RL}$ - receptor bound to ligand

RPM - rotations per minute

$\mathrm{R}_{\mathrm{S}}$ - resolution

RSD - relative standard deviation

$\mathrm{S} / \mathrm{N}$ - signal to noise

SDS - sodium dodecyl sulfate

sec -seconds

$\mathrm{T}$ - thymine

$\mathrm{V}_{\max }$ - maximum velocity of reaction

$v_{0}$ - initial velocity

$\eta$ - viscosity 


\section{CHAPTER 1:}

\section{Introduction to}

Capillary Electrophoresis, Binding Affinity, and Enzyme Kinetics 


\subsection{Capillary Electrophoresis}

Capillary electrophoresis was first utilized by Lukacs and Jorgenson for separation of peptides and amino acids in 1981[1]. Capillary electrophoresis separates ions based on their charge-to-size ratio. Two forces govern capillary electrophoresis separations, electroosmosis and electrophoresis.

Electroosmotic flow is a bulk flow, generated by the formation of a double layer at the surface of the fused silica capillary wall. The silanol groups along the wall are deprotonated at a pH higher than 2[2]. The negatively charged wall then attracts the positively charged cations in the running electrolyte. The layer of positively charged cations is attracted toward the cathode. The layer pulls along the next layers to produce a plug-shaped flow profile which produces less band-broadening compared to the pressure driven laminar flow.

Electrophoretic migration of the analytes is the movement of charged particles that is produced by an applied field[2]. Electrophoretic mobility $\left(\mu_{\mathrm{ep}}\right)$ of an analyte is a constant that is in proportion to the velocity and strength of the electric field of the CE. Electrophoretic mobility is directly proportional to the charge and size of the analyte as described in Equation 0.1. Where $q$ is the charge of the analyte, $\eta$ is viscosity of the running electrolyte solution, and $r$ is the hydrodynamic radius. 
Equation $0.1 \quad \mu_{\mathrm{ep}}=q /(6 \pi \eta r)$

The combination of the electrophoretic mobility $\left(\mu_{\mathrm{ep}}\right)$ and the electroosmotic mobility ( $\left.\mu_{\text {eof }}\right)$ yields the total apparent mobility $\left(\mu_{\mathrm{ap}}\right)$ of the analyte.

Equation $0.2 \quad \mu_{\mathrm{ap}}=\mu_{\mathrm{ep}}+\mu_{\mathrm{eof}}$

Under normal polarity capillary electrophoresis, cations have a positive electrophoretic mobility, while anions have a negative electrophoretic mobility.

Normal polarity capillary electrophoresis is shown in Figure 1-1. Here the potential is being applied to an anode (+). Electroosmotic flow is generated and flows toward the cathode (-). Each analyte ion exhibits its own electrophoretic mobility which drives the separation of ions. Neutrals are not separated in normal free zone electrophoresis. 


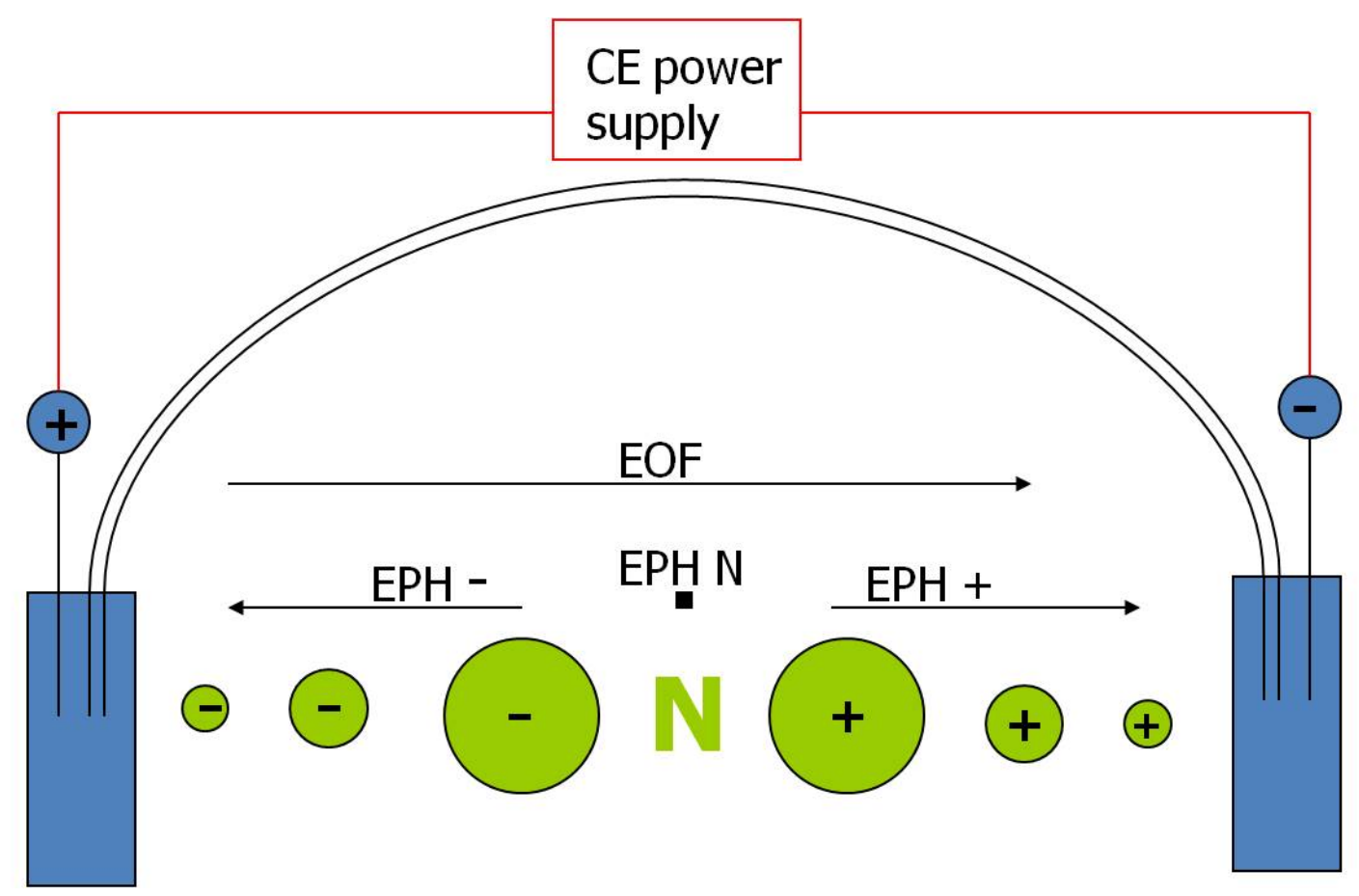

Figure 1-1: Basic capillary electrophoresis

Basic capillary electrophoresis instruments consist of a bare fused silica capillary, two buffer wells, two platinum electrodes, a high voltage direct current power supply usually for -30 to $30 \mathrm{kV}$, a pressure system, and a detector. The bare fused silica capillary has its ends immersed in the buffer wells. Bare fused silica capillary usually have an inner diameter of 25-100 $\mu \mathrm{m}$. Instruments are commercially available or can be constructed.

Multiple different separation modes are derived from capillary electrophoresis. Some of the modes are capillary zone electrophoresis (CZE)[1], Micellar electrokinetic chromatography (MEKC)[3, 4], capillary gel electrophoresis (CGE)[5], capillary isoelectric focusing (CIEF)[6], and affinity capillary electrophoresis (ACE)[7]. In order 
to produce a change in the analyte size and/or charge, affinity capillary electrophoresis requires analyte to react or to bind. The change in the charge-to-size ratio causes a shift in migration time between the bound/reacted or unbound/unreacted species. Affinity capillary electrophoresis is used for determination of biological constants such as the dissociation constant or the Michaelis constant.

\subsection{Dissociation Constant and Michaelis Constant}

\subsubsection{Calculation for Predicting the One-to-One Binding Curve with Excel}

The dissociation constant $\mathrm{K}_{\mathrm{d}}$ is important for comparing the strength of binding in many biological systems. In order to determine $\mathrm{K}_{\mathrm{d}}$ from the experiment, it is conventional to observe binding concentrations over multiple ligand concentrations. It is helpful to model the expected binding concentrations with Excel (Microsoft) before conducting the actual experimentation in order to help select and to observe an appropriate ligand concentration range. The graphical tool for determining experimental points to run requires only total reacted ligand, receptor concentrations, and a hypothesized $\mathrm{K}_{\mathrm{d}}$. The Excel sheet shown in Figure 1-2 solves for one-to-one binding and aids in selecting appropriate concentrations for the total reacted ligand and receptor concentrations, in order to select points that cover the entire curve. 
The Excel sheet is used to calculate the concentration of bound receptor ligand complex from the Equation 1.10, which is derived from the Equation 1.1 for the dissociation constant.

$$
\mathrm{R}_{\text {Free }}+\mathrm{L}_{\text {Free }} \leftrightharpoons \mathrm{RL}_{\text {Bound }}
$$

The equilibrium for one-to-one binding of ligand and receptor is shown above. The equation for the dissociation constant is Equation 1.1.

Equation $1.1 \quad \mathrm{~K}_{\mathrm{d}}=\left[\mathrm{L}_{\text {Free }}\right]\left[\mathrm{R}_{\text {Free }}\right] /\left[\mathrm{RL}_{\text {Bound }}\right]$

The total moles of receptor will equal the total concentration bound and free of ligand, therefore the concentrations can be set equal with Equation 1.2.

Equation $1.2\left[\mathrm{R}_{\text {Total }}\right]=\left[\mathrm{R}_{\text {Free }}\right]+\left[\mathrm{RL}_{\text {Bound }}\right]$

Equation 1.2 can be rearranged by subtracting [ $\left.R L_{\text {Bound }}\right]$ to solve for [ $\left.R_{\text {Free }}\right]$ to yield Equation 1.3.

Equation $1.3 \quad\left[\mathrm{R}_{\text {Free }}\right]=\left[\mathrm{R}_{\text {Total }}\right]-\left[\mathrm{RL}_{\text {Bound }}\right]$

The total moles of ligand will equal the total concentration bound and free of receptor, therefore the concentrations can be set equal with Equation 1.4.

Equation $1.4\left[\mathrm{~L}_{\text {Total }}\right]=\left[\mathrm{L}_{\text {Free }}\right]+\left[\mathrm{RL}_{\text {Bound }}\right]$ 
Equation 1.4 can be rearranged by subtracting [R $\left.L_{\text {Bound }}\right]$ to solve for [ $\left.\mathrm{L}_{\text {Free }}\right]$ to yield Equation 1.5.

Equation $1.5\left[\mathrm{~L}_{\text {Free }}\right]=\left[\mathrm{L}_{\text {Total }}\right]-\left[\mathrm{RL}_{\text {Bound }}\right]$

In order to solve for $\mathrm{Kd}$ in terms of the known variables, $\left[\mathrm{R}_{\text {Free }}\right]$ and $\left[\mathrm{L}_{\text {Free }}\right]$ from Equations 1.3 and 1.5 are substituted into Equation 1.1 to produce Equation 1.6

Equation 1.6 $\mathrm{K}_{\mathrm{d}}=\left(\left(\left[\mathrm{L}_{\text {Total }}\right]-\left[\mathrm{R} \mathrm{L}_{\text {Bound }}\right]\right) \times\left(\left[\mathrm{R}_{\text {Total }}\right]-\left[\mathrm{R} \mathrm{L}_{\text {Bound }}\right]\right)\right) /\left(\left[\mathrm{RL}_{\text {Bound }}\right]\right)$

In order to begin solving for the concentration of bound receptor ligand complex both sides of Equation 1.6 are multiplied by [RL $L_{\text {Bound }}$ to yield Equation 1.7.

Equation 1.7 $\mathrm{K}_{\mathrm{d}} \mathrm{x}\left[\mathrm{RL}_{\text {Bound }}\right]=\left(\left[\mathrm{L}_{\text {Total }}\right]-\left[\mathrm{R} \mathrm{L}_{\text {Bound }}\right]\right) \times\left(\left[\mathrm{R}_{\text {Total }}\right]-\left[\mathrm{RL}_{\text {Bound }}\right]\right)$

To simplify the right side of the Equation 1.7, multiplication is performed to acquire Equation 1.8.

Equation 1.8

$\mathrm{K}_{\mathrm{d}} \mathrm{x}\left[\mathrm{R} \mathrm{L}_{\text {Bound }}\right]=\left(\left[\mathrm{RL}_{\text {Bound }}\right]\right)^{2}-\left(\left[\mathrm{L}_{\text {Total }}\right]+\left[\mathrm{R}_{\text {Total }}\right]\right)\left(\left[\mathrm{RL}_{\text {Bound }}\right]\right)+\left(\left[\mathrm{L}_{\text {Total }}\right] \mathrm{x}\left[\mathrm{R}_{\text {Total }}\right]\right)$

Equation 1.8 is arranged as a polynomial equation equal to zero by subtracting both sides of Equation 1.8 by $\mathrm{K}_{\mathrm{d}} \mathrm{x}$ [RL $\left.\mathrm{R}_{\text {Bound }}\right]$ to yield Equation 1.9.

Equation $1.90=\left(\left[\mathrm{RL}_{\text {Bound }}\right]\right)^{2}-\left(\left[\mathrm{L}_{\text {Total }}\right]+\left[\mathrm{R}_{\text {Total }}\right]+\mathrm{K}_{\mathrm{d}}\right)\left(\left[\mathrm{RL}_{\text {Bound }}\right]\right)+\left(\left[\mathrm{L}_{\text {Total }}\right] \mathrm{x}\left[\mathrm{R}_{\text {Total }}\right]\right)$ 
Finally, solve for the concentration of the bound receptor ligand complex [RL $\left.L_{B o u n d}\right]$ in Equation 1.9 by using the quadratic formula. Equation 1.10 evolves and is the equation used for Excel modeling.

Equation 1.10

$\left[\mathbf{R L}_{\text {Bound }}\right]=$

$\left(\left(\left[\mathbf{L}_{\text {Total }}\right]+\left[\mathbf{R}_{\text {Total }}\right]+\mathbf{K}_{\mathrm{d})}\right) \pm\left(\left(\left[\mathbf{L}_{\text {Total }}\right]+\left[\mathbf{R}_{\text {Total }}\right]+\mathbf{K}_{\mathrm{d}}\right)^{2}-\mathbf{4}\left(\left[\mathbf{L}_{\text {Total }}\right] \mathbf{x}\left[\mathbf{R}_{\text {Total }}\right]\right)\right)^{1 / 2}\right) / 2$ 


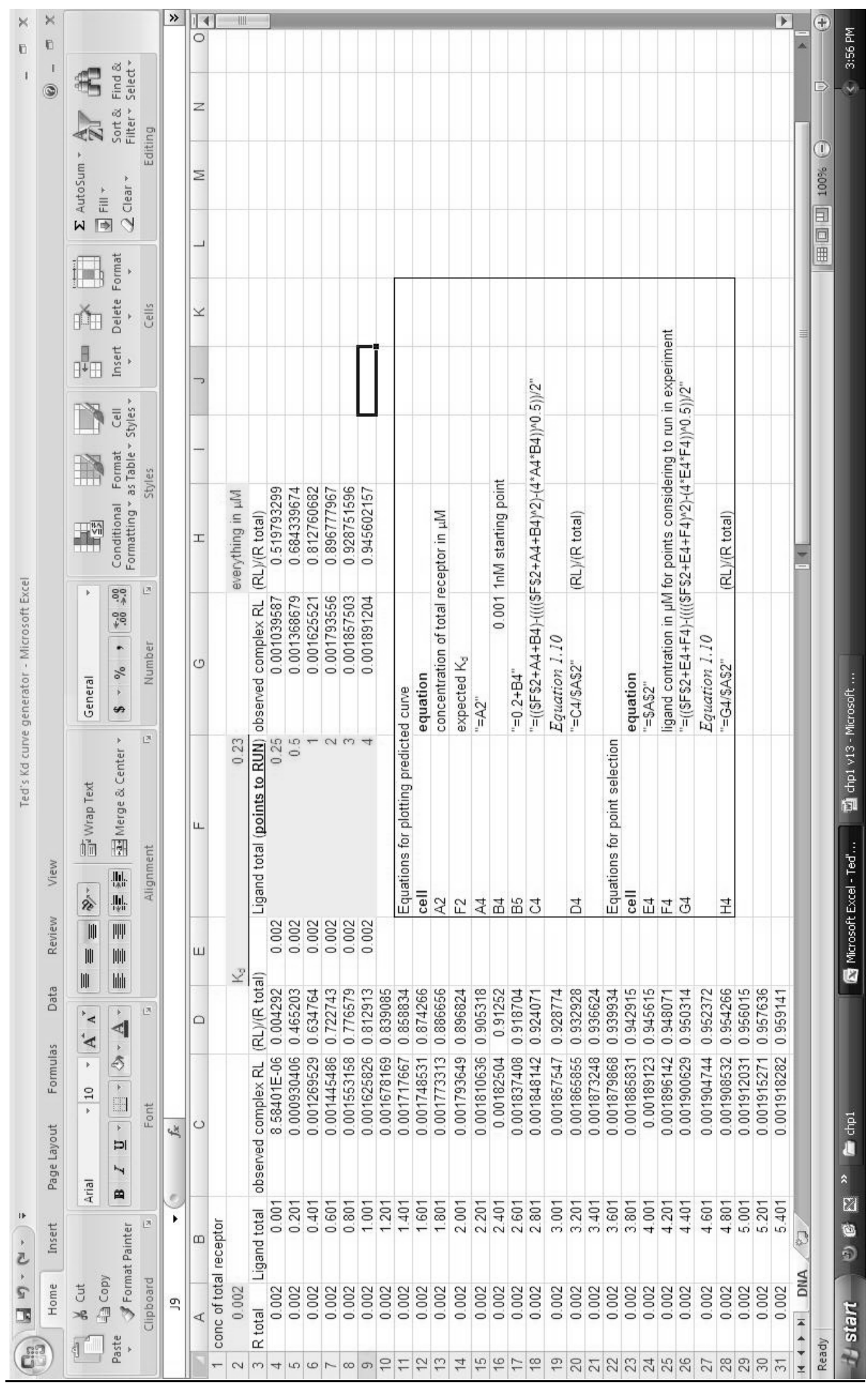

Figure 1-2: Predicting the one-to-one binding curve with Excel

Equation 1.10 is used for column $\mathrm{C}$ of the Excel sheet. 


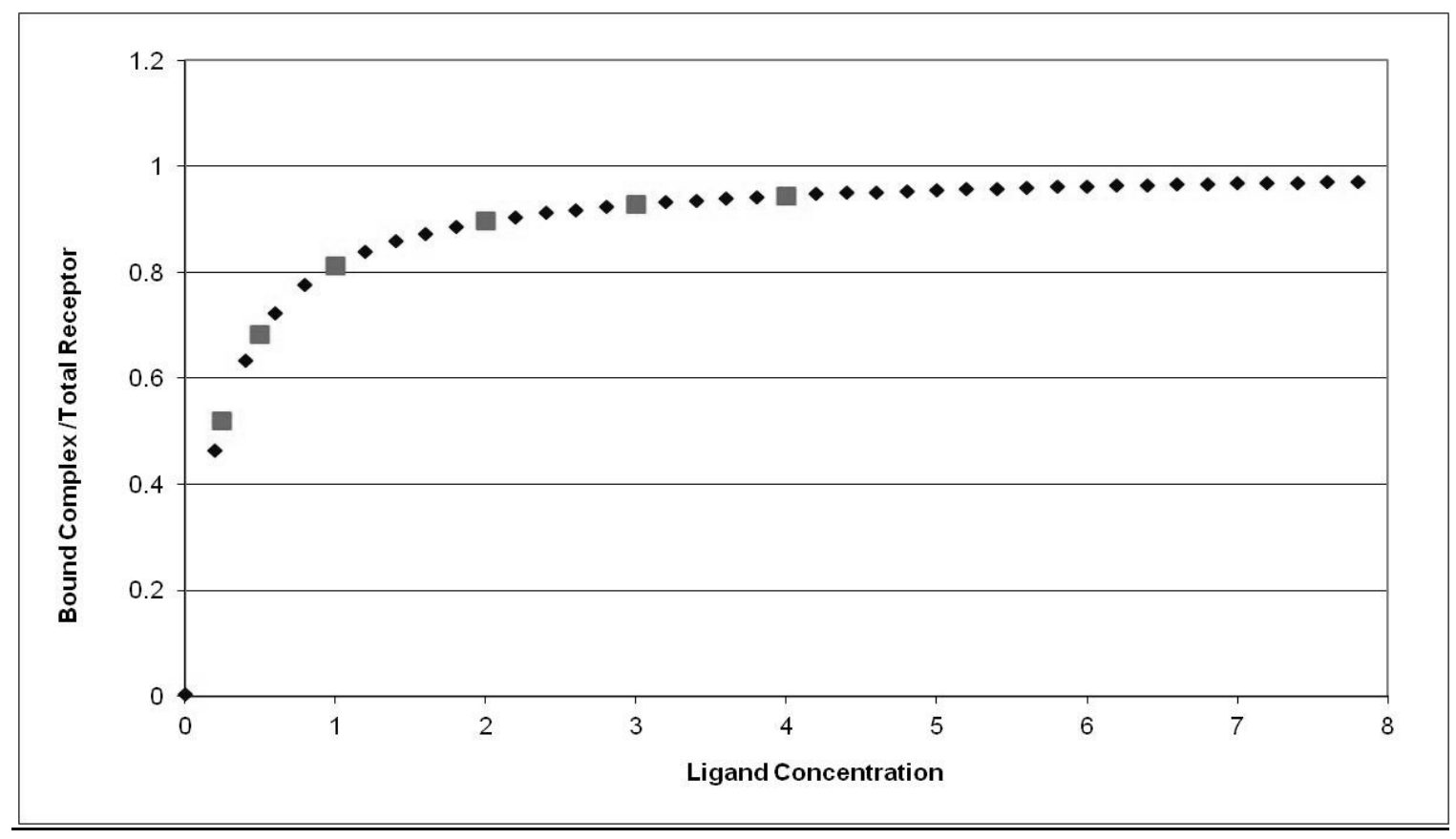

Figure 1-3: Predicting the one-to-one binding curve with Excel

Equation $1.10 \mathrm{Y}$ values come from column D in Excel and $\mathrm{X}$ values come from Column B. The bolded points are possible points to run for an experimental binding curve from column $\mathrm{F}$ and $\mathrm{H}$. 


\subsubsection{Conventional Calculation of $\mathbf{K}_{\mathrm{d}}$ from Experimental Results}

In order to determine $\mathrm{K}_{\mathrm{d}}$ from experimentation, it is conventional to observe binding over multiple ligand concentrations. Concentration of bound receptor ligand complex is plotted versus the free ligand concentration and is then fitted using nonlinear regression. The Equation 2.8 for the nonlinear regression is derived from the Equation 2.1 for the dissociation constant.

$$
\mathrm{R}_{\text {Free }}+\mathrm{L}_{\text {Free }} \leftrightharpoons \mathrm{RL}_{\text {Bound }}
$$

Again the equilibrium for one-to-one binding of ligand and receptor is shown above. The equation for the dissociation constant is therefore Equation 2.1.

Equation 2.1 $\mathrm{K}_{\mathrm{d}}=\left[\mathrm{L}_{\text {Free }}\right]\left[\mathrm{R}_{\text {Free }}\right] /\left[\mathrm{RL}_{\text {Bound }}\right]$

The total moles of receptor will equal the total concentration bound and free of ligand therefore the concentrations can be set equal with Equation 2.2.

Equation 2.2 $\left[\mathrm{R}_{\text {Total }}\right]=\left[\mathrm{R}_{\text {Free }}\right]+\left[\mathrm{RL}_{\text {Bound }}\right]$

Equation 2.2 can be rearranged by subtracting [RL $\left.L_{\text {Bound }}\right]$ and solving for $\left[\mathrm{R}_{\text {Free }}\right]$ in order to yield Equation 2.3.

Equation 2.3 $\left[\mathrm{R}_{\text {Free }}\right]=\left[\mathrm{R}_{\text {Total }}\right]-\left[\mathrm{RL}_{\text {Bound }}\right]$ 
In order to arrange the equation into known terms, [ $\left.\mathrm{R}_{\text {Free }}\right]$ from Equations 2.3 is substituted into Equation 2.1.

Equation $2.4 \mathrm{~K}_{\mathrm{d}}=\left(\left[\mathrm{L}_{\text {Free }}\right] \mathrm{x}\left(\left[\mathrm{R}_{\text {Total }}\right]-\left[\mathrm{RL}_{\text {Bound }}\right]\right)\right) /\left[\mathrm{RL}_{\text {Bound }}\right]$

To simplify Equation 2.4 the multiplication is performed thus yielding Equation 2.5.

Equation $2.5 \mathrm{~K}_{\mathrm{d}}=\left(\left(\left[\mathrm{L}_{\text {Free }}\right] \mathrm{x}\left[\mathrm{R}_{\text {Total }}\right]\right) /\left[\mathrm{RL}_{\text {Bound }}\right]\right)-\left[\mathrm{L}_{\text {Free }}\right]$

In order to simplify the equation, $\left[\mathrm{L}_{\text {Free }}\right]$ is added to both sides of Equation 2.5 to yield Equation 2.6.

Equation $2.6\left(\left[\mathrm{~L}_{\text {Free }}\right] \mathrm{x}\left[\mathrm{R}_{\text {Total }}\right]\right) /\left[\mathrm{RL}_{\text {Bound }}\right]=\mathrm{K}_{\mathrm{d}}+\left[\mathrm{L}_{\text {Free }}\right]$

([RL $\left.L_{\text {Bound }}\right]$ / [ $\left.R_{\text {Total }}\right]$ ) is the dependent variable in the relationship. Both sides of Equation 2.6 are then multiplied by ([RL $\left.L_{\text {Bound }}\right]$ / [ $\left.\mathrm{R}_{\text {Total }}\right]$ ) to produce Equation 2.7 .

Equation $2.7\left[\mathrm{~L}_{\text {Free }}\right]=\left(\mathrm{K}_{\mathrm{d}}+\left[\mathrm{L}_{\text {Free }}\right]\right) \mathrm{x}\left(\left[\mathrm{RL}_{\text {Bound }}\right] /\left[\mathrm{R}_{\text {Total }}\right]\right)$

In order to express the relationship in terms of ([RL $\left.\left.L_{\text {Bound }}\right] /\left[\mathrm{R}_{\text {Total }}\right]\right)$ and [ $\left.\mathrm{L}_{\text {Free }}\right]$, both sides of Equation 2.7 are divided by $\left(\mathrm{K}_{\mathrm{d}}+\left[\mathrm{L}_{\text {Free }}\right]\right)$ in order to yield Equation 2.8 where the independent variable $\left[\mathrm{L}_{\text {Free }}\right]$ is now on the left side of the equation.

Equation 2.8 (for nonlinear regression)

$$
\left[\mathbf{L}_{\text {Free }}\right] /\left(\mathbf{K}_{\mathbf{d}}+\left[\mathbf{L}_{\text {Free }}\right]\right)=\left(\left[\mathbf{R L}_{\text {Bound }}\right] /\left[\mathbf{R}_{\text {Total }}\right]\right)
$$


Now with Equation 2.8 a plot can be generated from experimental results by plotting $\mathrm{X}=$ [LFree $]$ and $Y=\left[R L_{\text {Bound }}\right] /\left[R_{\text {Total }}\right]$. The $K_{d}$ can be solved by nonlinear fitting in Graphpad software or in another nonlinear fitting software.

The plotted experimental results can be fit to Equation 2.9.

\section{Equation 2.9}

$$
\mathrm{Y}=\mathrm{X} /\left(\mathrm{K}_{\mathrm{d}}+\mathrm{X}\right)
$$




\subsubsection{Conventional Calculation of $K_{M}$ from Experimental Results}

The Michaelis-Menten equation is the basic equation for enzyme kinetics[8], where the initial velocity is $v_{0}=(d[\mathrm{P}] / d \mathrm{t})$ when steady state is achieved.

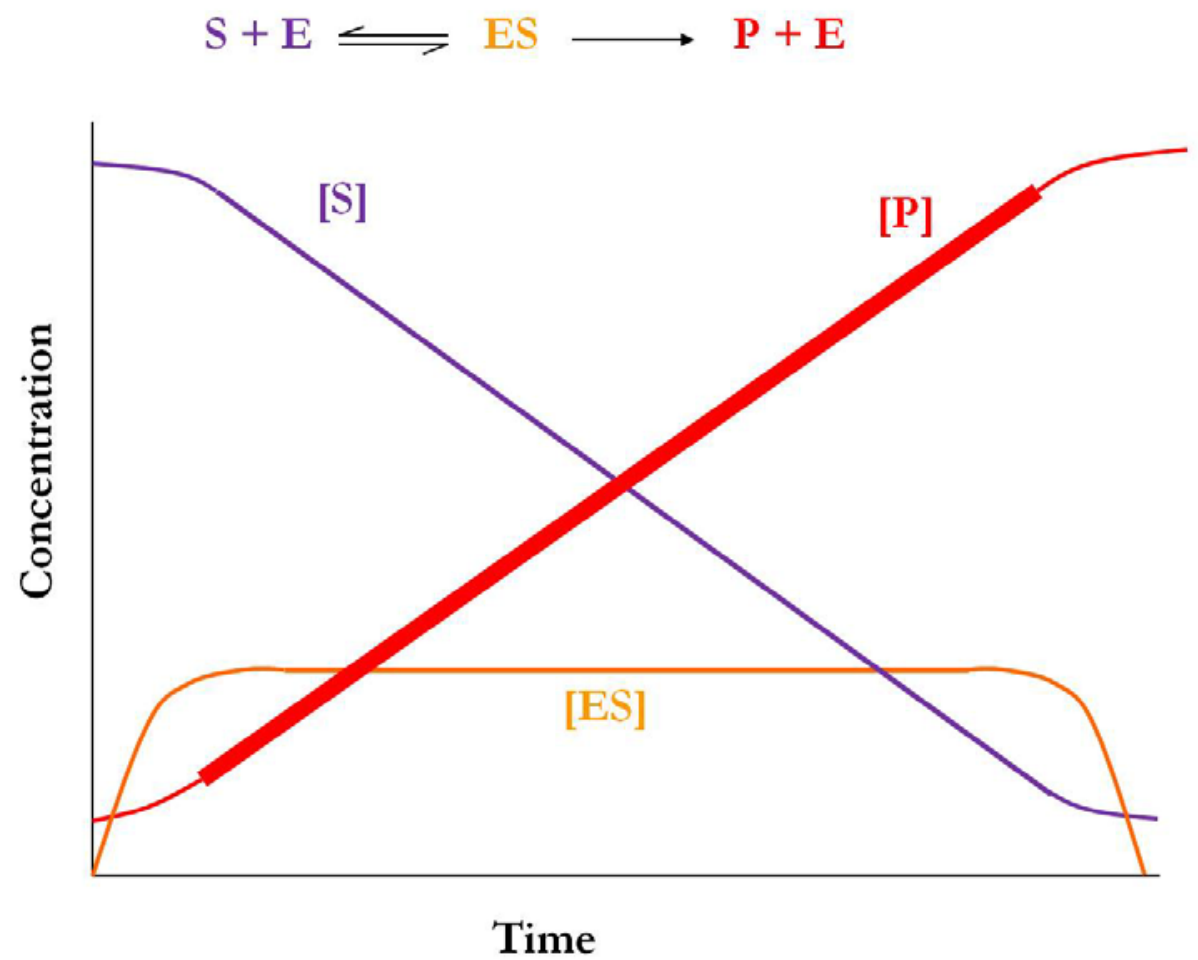

Figure 1-4: Adapted from [8], Reaction plot of a generic enzyme with a concentration of [E] reacting with substrate concentration of [S] to produce the product of concentration [P] 
Equation 1.4 (Michaelis-Menten equation)

$v_{\mathbf{0}}=\mathbf{V}_{\max }[\mathrm{S}] /\left(\mathrm{K}_{\mathrm{M}}+[\mathrm{S}]\right)$

$\mathrm{V}_{\max }$ is the maximal velocity of reaction when the enzyme is saturated. [S] is the substrate concentration. $K_{M}$ is the Michaelis constant where $K_{M}=\left(k_{-1}+k_{2}\right) / k_{1}$

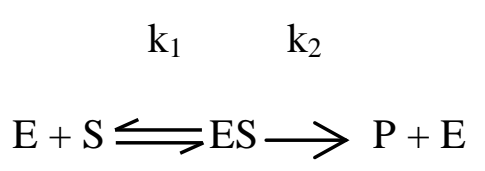

$\mathrm{k}_{-1}$

The Michaelis constant is useful in characterizing enzymes that catalyze the same substrate. It is also useful in understanding the catalytic efficiency of an enzyme, such that a smaller $\mathrm{K}_{\mathrm{M}}$ means that maximum catalytic efficiency is achieved at smaller concentrations of the substrate.

The Michaelis-Menten equation is a nonlinear function with a curve reminiscent of the $K_{d}$ functions. In order to analyze experimental results, it is conventional to plot the substrate concentration versus the initial velocity after steady state is achieved. Thus, the same nonlinear regression fit is required for the Michaelis-Menten equation as was true with the $\mathrm{K}_{\mathrm{d}}$ equations. 


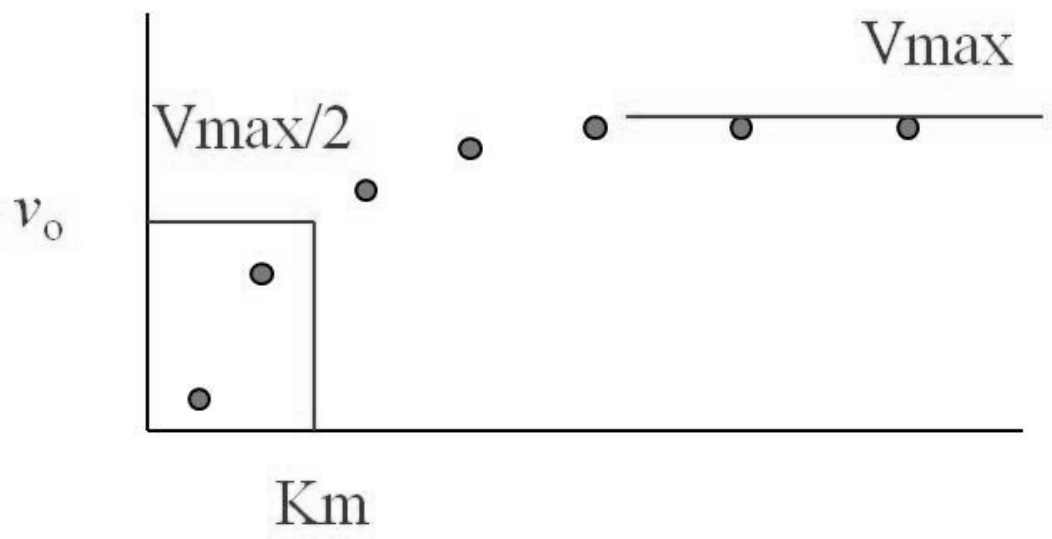

$[\mathrm{S}]$

Figure 1-5: Shows a typical Michaelis-Menten plot where each point is derived from the initial velocity (slope) of product formation. $\mathrm{K}_{\mathrm{m}}$ occurs at half of $\mathrm{V}_{\max }$. 


\subsection{Challenges for Chemical Separations}

Biomolecules have extreme importance from understanding cellular functions and biochemical pathways to understanding and early detection of diseases, such as cancer[9]. Bimolecules offer challenges for capillary electrophoresis separations. Many biomolecules are neutral; therefore, they comigrate in conventional free zone capillary electrophoresis, such as steroids and oligosaccharides. Many biomolecules are small molecules with similar structures, mass, and size making them harder to separate. Also, biomolecules can form very complex structures of same mass, but only differing in single bonding position such as oligosaccharides[10]. Biochemical pathways are interrelated, profiling multiple biomolecules of similar structure in a single sample is necessary to elucidate the effects upon biological systems, such as steroids with the endocrine system[11].

Different capillary electrophoresis modes can be utilized to separate biomolecules which are unable to be separated under free zone capillary electrophoresis. A new capillary electrophoresis electrospray mass spectrometry method to separate and detect labeled oligosaccharides is presented in chapter two. Neutral oligosaccharides are labeled to give charge for the capillary electrophoresis separation. Mass spectrometry offers accurate identification of complex biological analytes. The new method was used to monitor enzymatic hydrolysis of maltooligosaccharides are for $\alpha$-amyloglucosidase. The third chapter presents the use of $\mathrm{pH}$-mediated sample stacking with micellar electrokinetic capillary chromatography for measuring the binding affinity between two 
biological molecules. The binding affinity of $17 \beta$-estradiol with an immobilized DNA aptamer was measured. The dissociation constant was determined. The method was also used to screen binding affinity of the aptamer. 


\subsection{Bibliography}

[1] Jorgenson, J. W., Lukacs, K. D., Analytical Chemistry 1981, 53, 1298-1302.

[2] Harris, D. C., Quantitative Chemical Analysis, W. H. Freeman and Company 2003, p. 657.

[3] Terabe, S., Otsuka, K., Ichikawa, K., Tsuchiya, A., Ando, T., Analytical Chemistry 1984, 56, 111-113.

[4] Bykova, L., Holland, L. A., Electrophoresis 2008, 29, 3794-3800.

[5] Liu, J., Dolnik, V., Hsieh, Y. Z., Novotny, M., Analytical Chemistry 1992, 64, 13281336.

[6] Kilár, F., Electrophoresis 2003, 24, 3908-3916.

[7] McKeon, J., Holland, L. A., Electrophoresis 2004, 25, 1243-1248.

[8] Voet, D., Voet, J., Biochemistry, Wiley 1990, pp. 335-338.

[9] Hart, G. W., Copeland, R. J., Cell 2010, 143, 672-676.

[10] Zamfir, A., Peter-Katalinić, J., Electrophoresis 2004, 25, 1949-1963.

[11] Henley, D. V., Lindzey, J., Korach, K. S., Endocrinology: Basic and clinical principles 2005, pp. 49-65. 


\section{CHAPTER 2:}

Determination of Oligosaccharides Labeled with 1-Aminopyrene-3,6,8-Trisulfonic Acid by Capillary Electrophoresis Coupled to Electrospray Through a Coaxial Sheath Flow Interface with a Semi-Permanent Phospholipid Coating 


\subsection{Introduction}

The work presented here demonstrates the utilization of a semi-permanent phospholipid coating in capillary electrophoresis with a coaxial sheath flow interface for electrospray ionization mass spectrometric detection and has been published in a peer review journal[1]. Nonvolatile separation additives are rarely used for capillary electrophoresis mass spectrometry due to suppression of analyte ionization in the source. The system development went through several coupling interfaces before coaxial sheath flow was implemented. The separation instrumentation was custom-built. The pressure system and the electrical connection for the high voltage power supplies were also constructed in-house. The electroosmotic flow was measured in capillary, and the intraday reproducibility of the separation was determined.

Multiple applications for the system are demonstrated. The phospholipid coated capillary electrophoresis mass spectrometry is utilized for the separation of linear maltooligosaccharide and the separation of branched oligosaccharides. Further, enzyme reactions can be monitored for the determination of Michaelis-Menten constant. The $\alpha$ amyloglucosidase digestion is observed in time as well as the utilization of $\beta 1-4$ galactosidase to separate the branched isomeric oligosaccharides derived from fetuin. By coupling phospholipid coated capillary electrophoresis to electrospray, the separation method has the advantages of the semi-permanent coating with the benefits of using the mass spectrometer detector. 


\subsubsection{Basics of Electrospray Ionization}

Electrospray ionization was first reported by Fenn[2]; since that time it has grown to be one of the more prevalent ion sources for the detection of biological molecules, such as proteins[3] and oligosaccarides[4]. Electrospray mass spectrometry has the distinct advantage of more accurate identification of analytes, based on mass-to-charge, over other detection methods (UV visible absorbance and laser induced fluorescence). Electrospray is a soft ionization process which allows for the ionization of analytes. The ions produced by electrospray are often multiply-charged; thus high molecular weight analytes have smaller mass-to-charge ratios. The electrospray process occurs in several stages: Taylor cone formation, followed by drop formation, then drop shrinkage and fission, and finally gas-phase ion formation. Common electrospray sources have a solution containing analyte flowing through the capillary. A voltage is applied to the solution. In the solution, charged molecules separate based on their mobility in the applied field and charges build up on the surface of the solution. Once enough charged ions have built up at the surface, their electrostatic interactions begin to overcome the surface tension of the solution and a Taylor cone forms. When the field is strong enough to overcome the surface tension, a filament will emerge from the apex of the Taylor cone. As a result, charged droplets are released to stabilize the surface charge[5]. This process can be affected greatly by voltage and flow rate[6]. The process of drop formation can itself be classified into burst, pulsed, cone-jet, or multi-jet spray mode. Though all spray modes can be used for quantitative electrospray mass spectrometry, cone-jet is the most useful[7]. After droplets are formed, the solvent begins to evaporate and the droplets 
begin to shrink. Once the surface charge density is great enough that the coulombic interactions approach the Rayleigh charge limit, the surface tension is overcome causing the droplet to break apart. The droplet fission does not cause an equal volume splitting of the droplet. The droplet will eject a small volume droplet to stabilize the surface tension of the drop[8]. This shrinking and fission will continue until small droplets are formed which are small enough to release gas phase ions. There are two competing theories concerning the formation of the gas phase ions. The first, presented by Dole et al[9], is the single ion droplet theory. In this model, the droplets continue to experience evaporation and fission until the drop contains only a signal ion that is surrounded by solvent. The solvent will then evaporate leaving only a gas phase ion[9, 10]. The second theory was proposed by Iribarne and Thomson[11]. This ion evaporation theory differs from the single ion droplet theory in that charge repulsion in a droplet emits an ion with a single molecule solvent layer. The final result in both mechanisms is the gas phase ions which can then be passed through the mass analyzer. 


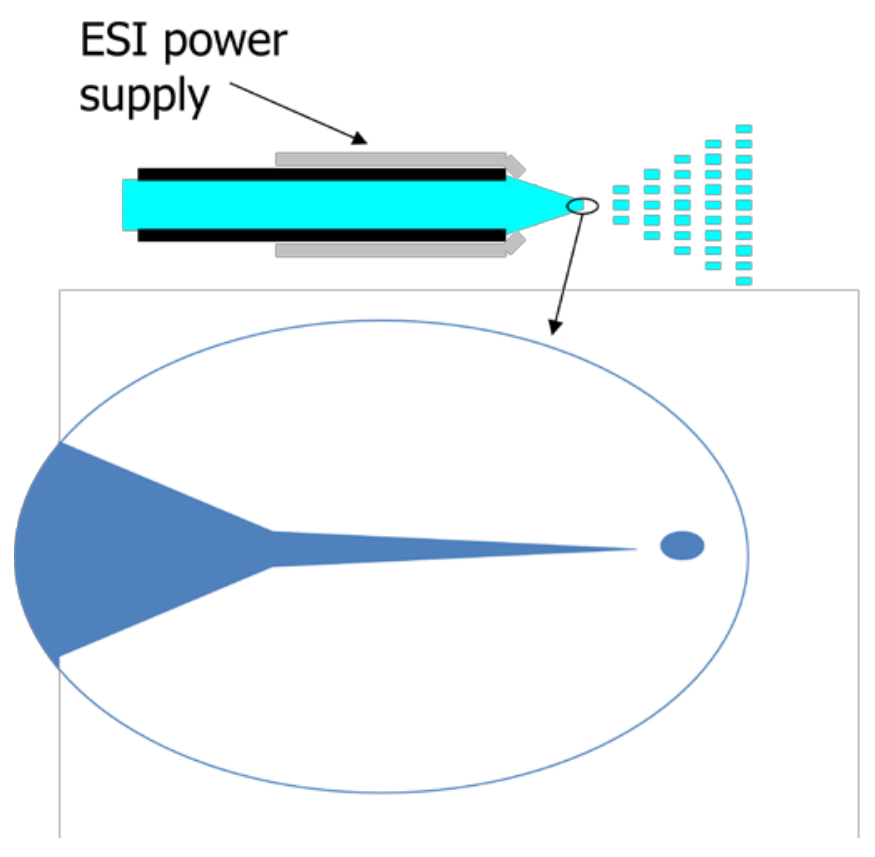

- Sheath Gas

- Analyte

Figure 2-1: Basic electrospray

\subsubsection{Coatings in Capillary Electrophoresis}

Capillary electrophoresis separations of oligosaccharides are generally accomplished by end-labeling with anionic fluorescent dyes to ensure that the oligosaccharides are charged and thus migrate in the electric field[12]. These separations are performed under reversed polarity often using a capillary with a covalently modified surface to suppress electroosmotic flow. These permanently modified capillaries can be purchased or synthesized, but have a limited lifetime, as the modified surface is hydrolyzed or accumulates nonspecifically adsorbed compounds that cannot be removed. In this case, the capillary must be replaced. Dynamic coatings, which are present in the running buffer and interact with the silica surface, are an alternative to covalent coatings. These coatings are simpler to create and can be easily regenerated. In general, dynamic 
coatings are incompatible with CE-ESI-MS as they are nonvolatile and desorb from the capillary surface. Some successful examples of dynamic coatings in CE-ESI-MS include N-methylpolyvinylpyridium[13], pullulan[14], and a two-layer electrostatic coating comprised of polybrene and dextran sulfate[15].

A third method of modification is the formation of a semi-permanent coating using double-chain surfactants that self-assemble on the capillary surface[16-19]. The long-range order in these materials increases the stability of the coating under a wide $\mathrm{pH}$ range. The semi-permanent coatings that have a net neutral charge, such as phosphocholine lipids, are resistive to nonspecific adsorption of proteins, and suppress the electroosmotic flow quite effectively[17, 18]. Regenerating the coating is straightforward, as it can be removed by flushing the capillary with non-aqueous solvent. Phospholipids in free solution are generally considered incompatible with ESI-MS as they suppress the ionization of targeted analyte. As a semi-permanent coating, phospholipids hold potential to suppress electroosmotic flow without preventing ionization and mass analysis with ESI-MS. To demonstrate the effectiveness of phospholipid coatings for reversed polarity, CE separations of 1-aminopyrene-3,6,8trisulfonic acid (APTS) labeled oligosaccharides are detected via negative mode ESI-MS in a custom-built CE system interfaced to ESI-MS. 
A)<smiles>CCCCCCCCCCCCCCCCCCCC(=O)OC[C@H](COP(=O)([O-])OCC[N+](C)(C)C)OC(=O)CCCCCCCC</smiles>

B)<smiles>CCCCCC(=O)OC[C@H](COP(=O)([O-])OCC[N+](C)(C)C)OC(=O)CCCCC</smiles>

Figure 2-2: Phospholipid Structures

A) DMPC (1,2-Dimyristoyl-sn-Glycero-3-Phosphocholine)

B) DHPC (1,2-Dihexanoyl-sn-Glycero-3-Phosphocholine)

\subsubsection{Coupling of Capillary Electrophoresis with Mass Spectrometry}

The separation current typical for CE, which ranges from 1-100 $\mu \mathrm{A}$, is at least an order of magnitude greater than that required for electrospray $(\leq 5 \mu \mathrm{A})$. Thus, these two currents must be decoupled, so that the conditions for the separation and electrospray can both be independently optimized. For most CE-MS systems, independent current is accomplished by using two modular power supplies. The performance specifications of 
the power supply must be considered. For example, a power supply that provides an internal path sinks the current to be delivered to the electrospray. The result of using low impedance, high voltage sources for CE-ESI-MS is that the power supply providing the lower potential will not reach the set voltage. Alternatively, low impedance power supplies may be used if a suitable resistor is placed in parallel with the electrospray circuit[20].

The compatibility of the running electrolyte and electrospray sheath liquid is another factor that must be considered prior to coupling capillary electrophoresis with ESI-MS. The background electrolytes used in CE are frequently zwitterionic and nonvolatile buffers, whereas the sheath liquid utilized in ESI must be volatile and often is modified with organic additives. The use of nonvolatile buffers in CE-MS is limited in ESI[21, 22]. Incorporating organic additives in the electrophoresis separation often increases the variability in migration time and susceptibility to Joule heating. The coaxial sheath flow interface also addresses the flow incompatibilities of CE ( nL/min) and ESI $(\sim \mu \mathrm{L} / \mathrm{min})$.

Three classifications of CE to MS interfaces are currently in use. All three interfaces share the common ability to produce stable electrospray after capillary electrophoresis by use of a second electrical connection. However, they do not achieve this in the same way. Therefore, they have different advantages and disadvantages. The coaxial sheath flow interface was the first CE-MS interface reported by Smith et al[23]. In this interface, the CE capillary is fed into a metal sleeve that carries a sheath liquid. 
The capillary is positioned to allow mixing of the CE eluent and sheath liquid at the tip of the metal tubing. The second CE electrode is in contact with the sheath liquid to complete the CE circuit. The coaxial sheath flow interface is simple and rugged. However, the sheath liquid dilutes the analyte which raises the limits of detection (LOD). Since the coaxial sheath flow interface is offered in many commercial instruments, it has been the most commonly used interface for research[4].

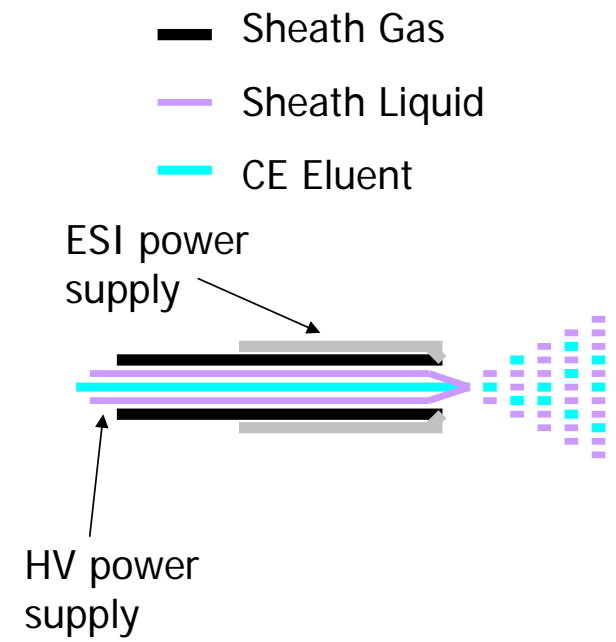

Figure 2-3: Coaxial sheath flow interface

Another interface is the liquid junction interface which was first reported by Henion et al[24]. In this interface the CE capillary is positioned within a few micrometers of the entrance of the ESI capillary. The second CE electrode is in the reservoir with the interfacing capillaries. This interface offers simple coupling to most electrospray sources. Unfortunately, the capillary alignment is often tedious, and any 
misalignment decreases sensitivity and separation efficiency. The dead volume of the junction limits the LOD because of analyte dilution.

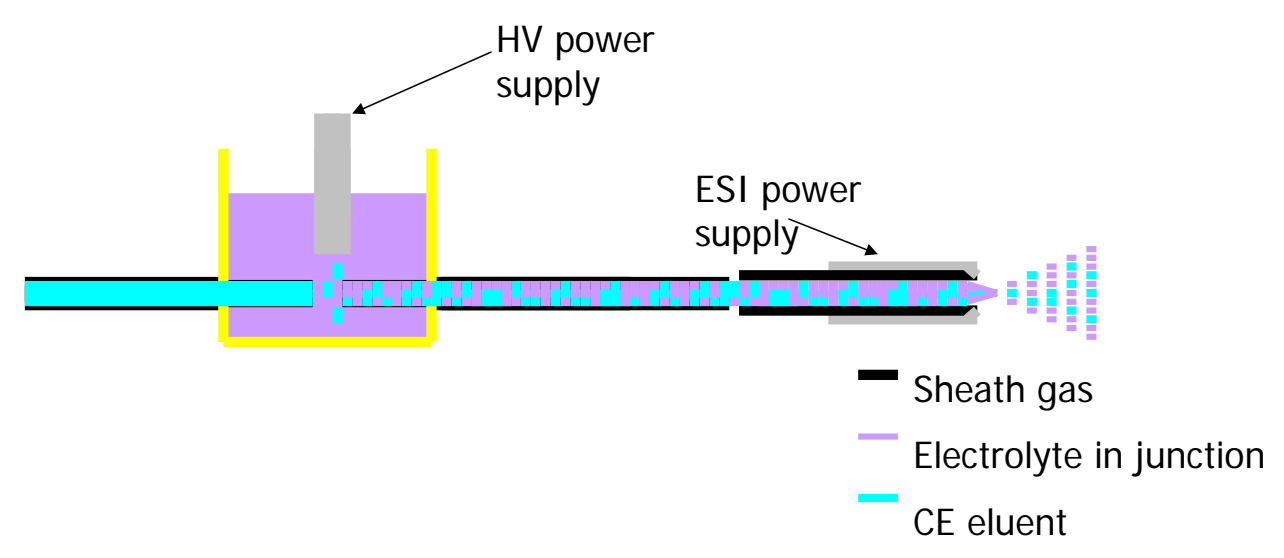

Figure 2-4: Liquid junction interface

The third class of interfaces is the sheathless interfaces. Sheathless interfaces all share some common traits. All can be used with nanospray which better matches the flow rates of CE. There is no dilution of the analytes due to sheath liquids. With many sheathless interfaces, low to sub-femtomole mass limits of detection have been reported for many analytes. In order to sustain a stable electrospray, a second electrode must be in place after the CE separation capillary. The second electrical connection provides potential for the spray as well as potential for the second electrode of the CE. This group of interfaces has received the most attention in development in recent years[25]. The first sheathless interface was described by Smith et al[26]. In this interface class the second 
electrode can be positioned in several ways. The end of the CE capillary is coated with a metal or conductive polymer[26, 27]. A wire can be inserted in the end of the CE capillary through a hole in the side of the capillary[28, 29]. It has been shown that by positioning the end of the CE capillary close to the inlet of the mass analyzer that the circuits can be completed through the air[30]. The second electrode is positioned in a buffer reservoir that allows ions to migrate through the side of the capillary, through a porous junction, or through microdialysis tubing[31, 32]. The second electrode can be placed in a micro-tee between the exit of the CE capillary and the entrance of the electrospray capillary[33]. However, these sheathless interfaces still have some disadvantages. All require delicate construction. The metal coating methods are not durable. Mechanically drilled pinholes are not reproducible and are very fragile. The porous junction requires HF etching. With many sheathless interfaces, low- to subfemtomole mLODs have been reported for many analytes, and pre-concentration can be used to lower the LOD by loading more analyte in the CE.[25] Of the three interfaces, the coaxial sheath flow is the simplest to implement and allows for the separation buffer to be different from the sheath liquid. Liquid junction and sheathless interfaces require delicate construction and are usually fragile. The coaxial sheath flow interface being the most rugged without delicate failure points has shown to be the most popular interface, becoming commercially available on major mass spectrometers' electrospray sources. 


\subsection{System Selection: Coaxial Sheath Flow}

The coaxial sheath flow interface was chosen for its rugged and simple design. While the coaxial sheath flow interface does dilute the sample, it offers easier coupling. The coaxial sheath flow interface has a preset centering positioning for the capillary which makes the electrospray more easily optimized. The coaxial interface does not require any degradable coatings, fragile tips, or etched capillaries which would make the design more difficult to collect the nonvolatile solutions from the electrospray tip during flushes. This interface design utilizes the ability of phospholipids to form a semipermanent coating. Applying a pressure assist to the separation maintains fluid flow to the ion source.

\subsection{Materials and Methods}

\subsubsection{Chemicals}

Maltooligosaccharide standards, MOPS, $\alpha$-amyloglucosidase, asialofetuin, and sodium hydroxide were purchased from Sigma-Aldrich (St. Louis, MO, USA). Isopropyl alcohol, methanol, and $\mathrm{CaCl}_{2}$ were purchased from EMD Biosciences (La Jolla, CA, USA). 1-Aminopyrene-3,6,8-trisulfonic acid (APTS) was purchased from Biotium (Hayward, CA, USA). Sodium cyanoborohydride $\left(\mathrm{NaCNBH}_{3}\right)$ was purchased from Strem Chemicals (Newburyport, MA, USA). Triethylamine, acetonitrile, ammonium hydroxide, acetic acid, and citric acid were purchased from Fisher Scientific (Pittsburgh, 
PA, USA). The lipids, 1,2-dimyristoyl-sn-glycero-3-phosphocholine (DMPC) and 1,2dihexanoyl-sn-glycero-3-phosphocholine (DHPC), were purchased from Avanti Polar Lipids (Alabaster, AL, USA). A peptide $N$-glycosidase (PNGase F) kit and $\beta 1-4$ galactosidase were purchased from New England Biolabs (Ipswich, MA). The PNGase F kit was supplied with a G7 10X reaction solution comprised of $0.5 \mathrm{M}$ sodium phosphate buffered at $\mathrm{pH} 7.5$, a glycoprotein denaturing solution containing 5\% SDS and 0.4M dithiothreitol, and a $10 \%$ solution of the nonionic surfactant NP-40. Deionized water was obtained from an Elga Purelab ultra water system (Lowell, MA).

\subsubsection{Instrumentation}

The CE-MS system was custom built consisting of the coaxial sheath flow interface connected to the CE capillary and custom pressure system. For all separations reported, a potential of $-25 \mathrm{kV}$ was applied at the cathodic reservoir. The anode used for $\mathrm{CE}$ and the ESI potential were maintained at an applied potential of $-3.5 \mathrm{kV}$. This was accomplished using the electrical connection manufactured for the commercial ESI source which is connected to the stainless steel needle used in the source. A stable current of $5 \mu \mathrm{A}$ within the CE capillary was measured. The CE capillary extends less than one millimeter out of the stainless steel needle of the source. The capillary position is important to maintain stable CE current and to efficiently transfer analyte to the ESI. The capillary was manually adjusted and then fixed in place in the source with a fingertight fitting (Idex corp., Oak Harbor, WA, USA). 
The CE-ESI-MS system is depicted in Figure 2-5. The commercial ESI source is designed with inlets for a sheath liquid and a sheath gas. The sheath liquid was delivered using a syringe pump connected to the sheath liquid inlet. No sheath gas was applied during separations. However, a sheath gas was applied during flushing to prevent flush solutions from contaminating the internal gas lines within the source. The electrospray source (LCQ DECA, Thermo Scientific, Waltham, MA, USA) accepts a $190 \mu \mathrm{m}$ outer diameter capillary. The fused silica capillary was $85 \mathrm{~cm}$ long, $50 \mu \mathrm{m}$ inner diameter, and $190 \mu$ m outer diameter. Two high voltage power supplies (CZE1000R, Spellman, Hauppauge, NY, USA) apply the potential that drives the ESI and CE. An $88 \mathrm{M} \Omega$ resistor in parallel to the electrospray circuit allows independent control of the CE and ESI potentials. The ends of the capillary are maintained at the same height to prevent siphoning. To maintain reproducible separations, three different pressure regulators were used in-line with the gas cylinder and selected with manual valves. One regulator was set at $140 \mathrm{kPa}(20 \mathrm{psi})$ and used to flush the capillary. The second regulator was set at 14 $\mathrm{kPa}$ (2 psi) and connected to a solenoid valve controlled by a digital timer to provide reproducible sample injections. The third regulator had a gauge ranging from $0-34 \mathrm{kPa}$ (0-5 psi). This low-pressure regulator was used to supply a $1.7 \mathrm{kPa}(0.25 \mathrm{psi})$ pressure assist. The pressure assist during the separation is required as the separation current (i.e. the current flow between the CE and the ESI) drops to zero in the absence of pressureassisted fluid flow. 

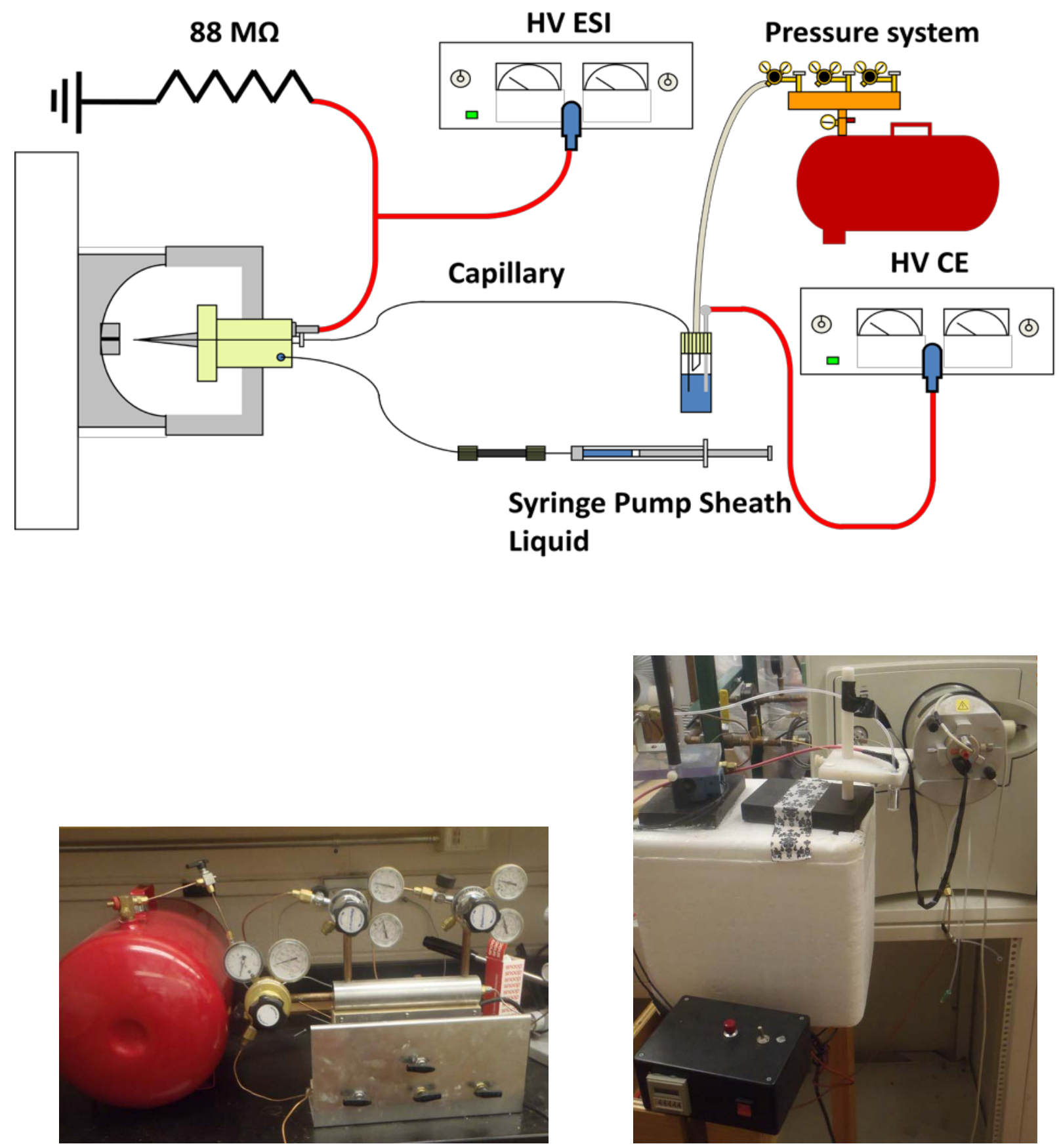

Figure 2-5: A schematic diagram of the custom-built CE system and ESI interface. The system integrates the commercial electrospray source with the separation capillary, a pressurized buffer vial, a pressure regulator system, two independent high-voltage power supplies, an $88 \Omega \mathrm{M}$ resistor, and a syringe pump for the sheath liquid. 
The mass spectrometer integrated in the system was an LCQ DECA (Thermo Scientific), which was controlled by the LCQ tune v.1.1 software. Data analysis was done using the Xcaliber qual browser v1.1 software provided by the manufacturer. The temperature of the heated capillary was set at $250{ }^{\circ} \mathrm{C}$. During CE runs, the ion trap was operated in select ion mode at appropriate $\mathrm{m} / \mathrm{z}$ values to maximize the $\mathrm{S} / \mathrm{N}$ of the analytes. The $\mathrm{m} / \mathrm{z}$ detection windows for linear oligosaccharides were 795.5-796.5, 714.5-715.5, 633.5-634.5, 552.5-553.5, and 471.5-472.5. For branched glycans these values were 692.8-693.8 (AI), 652.1-654.0 (AII digest), 706.1-707.5 (FII digest), and 814.0-816.3 (AII/FII). The solution used for the sheath flow (50\% isopropyl alcohol, 50\% $15 \mathrm{mM}$ aqueous ammonium acetate) was made fresh daily. To achieve stable spray and acceptable ionization efficiency with negative mode ionization of APTSoligosaccharides as well as glycans, a minimum of $50 \%$ isopropyl alcohol and a makeup flow rate of at least $2 \mu \mathrm{L} /$ min were required. The mass spectrometer was calibrated using standards recommended by the manufacturer (caffeine, MRFA, Ultramark) and tuned using maltoheptaose.

\subsubsection{Capillary Preparation}

The capillary was flushed using a pressurized system previously discussed. During flushes, precautions were taken to prevent the solutions used for the flushes from contaminating the ESI or mass analyzer. The source droplets expelled from the capillary were collected by touching the end of the capillary to a low-lint light duty tissue wiper (VWR, Bridgeport, NJ, USA). Sheath gas was applied at a pressure of $1.7 \mathrm{kPA}$, and the 
sheath liquid was delivered at a flow rate of $1 \mu \mathrm{L} / \mathrm{min}$. Each morning the capillary was flushed at $140 \mathrm{kPa}$ at the cathodic reservoir with $1.0 \mathrm{M}$ sodium hydroxide (30 min), deionized water (15 min), methanol (15 min), deionized water (15 min), phospholipid (20 min), and followed by BGE comprised of $15 \mathrm{mM}$ ammonium acetate buffered at $\mathrm{pH}=$ 4.5 (3 min). The solution used as the phospholipid coating was a 5\% solution of lipid with $[\mathrm{DMPC}] /[\mathrm{DHPC}]=0.5,95 \%$ MOPS buffered to $\mathrm{pH}=7,1.25 \mathrm{mM} \mathrm{CaCl}_{2}$. The phospholipid was prepared by dissolving DMPC and DHPC in MOPS and then subjecting the preparation to 3 freeze-thaw cycles. The solution was centrifuged for 10 minutes at 10,000 RPM, aliquoted, and frozen until use. Between each electrophoresis run, the capillary was flushed with phospholipid (3 min) and followed by BGE (2 min). The sample was injected into the separation capillary using pressure ( 3 sec 2 psi). The sample injection was followed with a pressure injection of BGE (3 sec 2 psi).

\subsubsection{Glycan Sample Preparation and Derivatization}

Branched glycans were harvested from asialofetuin using a commercially available PNGase F kit. A $600 \mu$ g sample of asialofetuin was dissolved in $9 \mu \mathrm{L}$ water to which $1 \mu \mathrm{L}$ of denaturation solution (5\% SDS and $0.4 \mathrm{M}$ dithiothreitol) was added. The $10 \mu \mathrm{L}$ aqueous solution was heated to $95^{\circ} \mathrm{C}$ for 10 minutes. Reagents provided in the deglycosylation kit were combined as follows: $2 \mu \mathrm{L}$ of 10X G7 reaction buffer, $2 \mu \mathrm{L}$ of NP-40 solution, $2 \mu \mathrm{L}$ of PNGase F solution. Four $\mu \mathrm{L}$ of deionized water were added to this solution, and the reaction was allowed to proceed overnight at $37^{\circ} \mathrm{C}$. The protein was then precipitated by adding $60 \mu \mathrm{L}$ of ice-cold ethanol. The solution was centrifuged 
at $10,000 \mathrm{rpm}$ at $4^{\circ} \mathrm{C}$ for 10 minutes. The liquid fraction was removed, evaporated to dryness using a Savant SpeedVac concentrator (ThermoScientific, Waltham, MA), and then labeled with APTS.

Linear maltooligosaccharides were labeled with APTS using a procedure reported previously[34]. Briefly, 5.0 $\mu \mathrm{L}$ of $0.5 \mathrm{M}$ linear maltooligosaccharide in $2.0 \mathrm{M}$ acetic acid was added to $5.0 \mu \mathrm{L}$ of $0.1 \mathrm{M}$ APTS in $15 \%$ acetic acid and to $10 \mu \mathrm{L}$ of $0.5 \mathrm{M} \mathrm{NaCNBH}_{3}$ freshly prepared in $15 \%$ acetic acid. The reaction was incubated at $55^{\circ} \mathrm{C}$ for 2 hours. The reaction mixture was then diluted with deionized water to bring the total volume to $165 \mu \mathrm{L}$. The labeling procedure used for branched glycans recovered from asialofetuin, was similar to that for maltooligosaccharides, except that excess APTS was used in the labeling reaction. The dried glycans were combined with $1 \mu \mathrm{L} 0.2 \mathrm{M}$ APTS in $1.2 \mathrm{M}$ citric acid and $1 \mu \mathrm{L}$ of $1 \mathrm{M} \mathrm{NaCNBH}$. The reaction was incubated for 2 hours at $55^{\circ} \mathrm{C}$ and then diluted by adding $100 \mu \mathrm{L}$ of deionized water. 
<smiles>[R]C1OC(O)C([R])C([R])C1[R]</smiles><smiles>[R]C(O)C([R])C([R])C([R])C=O</smiles>

$+$

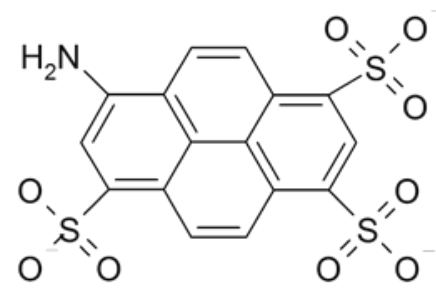

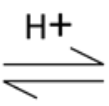<smiles>[R]C(O)C([R])C([R])C([R])/C=N/c1cc(S(=O)(=O)[O-])c2ccc3c(S(=O)(=O)[O-])cc(S(=O)(=O)O)c4ccc1c2c34</smiles>

$\mathrm{NaBH}_{3} \mathrm{CN}$<smiles>[R]C(O)C([R])C([R])C([R])[CH]Nc1cc(S(=O)(=O)[O-])c2ccc3c(S(=O)(=O)[O-])cc(S(=O)(=O)O)c4ccc1c2c34</smiles>

Figure 2-6: Derivatization of sugar

Complex forming ions must be removed from the samples to prevent adduct formation, as this increases the complexity of the mass spectra and makes interpretation more difficult. Therefore, the linear maltooligosaccharides were desalted with anion exchange LC. An amine guard column (Adsorbosphere $\mathrm{NH}_{2}$ guard column cartridge, Alltech, Deerfield, Il, USA) was equilibrated with deionized water at a flow rate of 1 $\mathrm{mL} / \mathrm{min}$. A $30 \mu \mathrm{L}$ sample of a linear maltooligosaccharide reaction mixture was injected into the column. The maltooligosaccharide was retained at the head of the column, which was rinsed with deionized water for 15 minutes at a flow rate of $1 \mathrm{~mL} / \mathrm{min}$. The maltooligosaccharide was then eluted using a mobile phase comprised of aqueous $80 \mathrm{mM}$ ammonium acetate buffered at $\mathrm{pH}=7.0$. The linear maltooligosaccharides were 
collected from the end of the column, evaporated to dryness with a Savant SpeedVac concentrator, and reconstituted in $15 \mathrm{mM}$ ammonium acetate at $\mathrm{pH} 4.5$.

Branched glycans labeled with excess APTS were desalted using a Discovery DPA-6S solid phase extraction cartridge (50 mg packing material, Supelco, Bellefonte, PA, USA). Before use, the extraction cartridge was rinsed with $3 \mathrm{~mL}$ of a solution comprised of 95\% acetonitrile and 5\% deionized water. The reaction mixture was reconstituted in a solution comprised of 95\% acetonitrile 5\% deionized water and applied to the cartridge. The cartridge was first flushed with $6 \mathrm{~mL}$ of $95 \%$ acetonitrile and $5 \%$ water and then flushed with $1 \mathrm{~mL}$ of $50 \mathrm{mM}$ triethylamine in 95\% acetonitrile and 5\% water. The labeled oligosaccharides were then eluted with $1 \mathrm{~mL}$ of $50 \mathrm{mM}$ triethylamine in water. In addition to eliminating sodium, this process removed unreacted APTS.

The enzymatic digestion of maltoheptaose was accomplished using $\alpha$ amyloglucosidase. A solution of $0.01 \mathrm{unit} / \mu \mathrm{L}$ of $\alpha$-amyloglucosidase was added to $20 \mu \mathrm{L}$ of desalted maltoheptaose reconstituted in $15 \mathrm{mM}$ ammonium acetate buffered at $\mathrm{pH} 4.5$ and incubated at $37^{\circ} \mathrm{C}$ until sampling. The reaction required no purification to remove sodium ions. Enzyme hydrolysis of the FII and AII glycans was accomplished using $\beta 1$ 4 galactosidase. A $60 \mu \mathrm{L}$ sample of labeled oligosaccharides reconstituted in $15 \mathrm{mM}$ ammonium acetate buffered at $\mathrm{pH} 4.5$ was combined with $7 \mu \mathrm{L}$ of $50 \mathrm{mM}$ citrate buffered at $\mathrm{pH} 6.0$ and $3.5 \mu \mathrm{L}$ of an aqueous solution of $\beta 1-4$ galactosidase. The reaction was incubated overnight at $37^{\circ} \mathrm{C}$. The cleaved reaction products were recovered using a DPA-6S solid phase extraction cartridge with the concentration and elution procedure 
described for purification following APTS labeling. The glycans eluted from the cartridge were further treated using a 1-kDa molecular weight cut-off filter (Pall, Port Washington, NY, USA) in order to remove any remaining sodium ions. Prior to use, the molecular weight cut-off filter was rinsed with $3 \mathrm{~mL}$ of deionized water via centrifugation at $2500 \mathrm{G}$. The fraction eluted from the DPA-6S extraction cartridge was applied to the filter. Six mL of deionized water were rinsed through the sample at 2500 G. The desalted solution containing oligosaccharide was then evaporated to dryness using a Savant SpeedVac concentrator and reconstituted in background electrolyte. 


\subsection{Results and Discussion}

\subsubsection{Selection of Negative Mode Ionization}

CE can be coupled to ESI-MS with positive or negative mode ionization. The ESI was operated in negative mode for several reasons. In general, negative mode electrospray produces less complex spectra[35, 36]. Phospholipids are generally not incorporated in positive mode ESI-MS, because these compounds substantially suppress ionization of the targeted analyte[37]. In the current system, phospholipids are not observed in the background of the negative electrospray when the mass analyzer is operated in full scan. Implementing negative mode ionization with reversed polarity capillary electrophoresis is straightforward. The CE is held at a more negative potential than the electrospray tip, and the skimmer plate in most mass analyzers equipped for ESI is traditionally maintained at ground by the instrument. The derivatization of oligosaccharides with multiply-charged labels reduces the mass-to-charge ratio of large oligosaccharides to a range suitable for a quadrupole ion trap mass analyzer.

Oligosaccharides can be easily labeled 1:1 with anionic fluorophores, and separations of derivatized oligosaccharides using CE are accomplished with a variety of anionic labels including APTS[4, 38-40]. The anionic label is critical to resolve the oligosaccharides electrophoretically and makes them amenable to negative mode ESI as well. These separations are typically accomplished with reversed polarity under suppressed EOF. 


\subsubsection{EOF Suppression by Phospholipid Coating}

The EOF must be suppressed or directed toward the detector in the CE-ESI-MS system to promote stable electrospray. When the EOF is directed toward the cathodic reservoir at the site of injection, this competing flow hinders the transfer of analyte into the mass analyzer. In addition, the spray stability is dependent upon flow rate, and flow instability in EOF may be observed as an instability in the ESI. To prevent these consequences, the EOF can be suppressed using different strategies. The EOF may be suppressed by using an acidic BGE $[39,41]$. It may also be eliminated by using a capillary in which the surface has been rendered neutral with a covalent surface coating[40, 42-44]. Covalent coatings have a limited lifetime, as the stability of the coating can be reduced at acidic $\mathrm{pH}$, at basic $\mathrm{pH}$, or in the presence of biopolymers that foul the surface. Covalently modified capillaries with an i.d. $\geq 50 \mu \mathrm{m}$ are commercially available. Capillaries of smaller i.d. must be chemically modified in-house. Semipermanent coatings are an exciting alternative to covalently modified capillaries. Phospholipids self-assemble on the surface of the fused silica capillary, forming a stable bilayer. Semi-permanent coatings with phosphocholine lipids are zwitterionic with a net charge of zero[17, 18]. In this method, the formation of the phospholipid coating is facilitated simply by flushing the capillary with a 95\% aqueous phospholipid solution $([\mathrm{DMPC}] /[\mathrm{DHPC}]=0.5)$, followed by a rinse with BGE. The EOF obtained using a 15 $\mathrm{mM}$ ammonium acetate solution was measured using the method of Williams and Vigh[45]. These experiments demonstrated that under reversed polarity, the EOF moved 
toward the detection window at $4.0 \times 10^{-6} \pm 0.6 \times 10^{-6} \mathrm{~cm}^{2} / \mathrm{Vs}$ at a $\mathrm{pH}$ of $4(n=5)$ and 1.8 x $10^{-5} \pm 0.2 \times 10^{-6} \mathrm{~cm}^{2} /$ Vs at a $\mathrm{pH}$ of $7(n=5)$.

\subsubsection{Selection of Running Electrolyte and Optimization of Flow Rate}

Some optimization of the CE and ESI was required prior to applying the method to oligosaccharides. Current flow must be maintained between the CE and ESI, so that the separated analyte is transferred into the mass analyzer. In the absence of EOF, the $\mathrm{pH}$ of the BGE had little influence on separation and a BGE comprised of $15 \mathrm{mM}$ ammonium acetate at $\mathrm{pH}=7.0$ was used (See Figure $2-7$ ). At this $\mathrm{pH}$, the electrospray current occasionally dropped to zero. This transient instability was remedied by changing the BGE to $15 \mathrm{mM}$ ammonium acetate at $\mathrm{pH}=4.5$. In addition, the CE-MS method performed better when the $\mathrm{pH}$ of the BGE and fluid used for sheath flow were the same. Therefore, both the BGE and coaxial sheath flow were adjusted with acetic acid to $\mathrm{pH}=4.5$. Stable electrospray was maintained at a sheath flow rate of $2 \mu \mathrm{L} / \mathrm{min}$.

Although the ESI was stable above this value, higher sheath flow rates diluted the analyte prior to mass analysis and adversely affected the response. The electrospray stability was improved with the addition of 50\% isopropyl alcohol, which did not affect the stability of the phospholipid coating. The isopropyl alcohol was not included in the BGE. Sheath liquids with less than 50\% isopropyl alcohol did not result in stable electrospray. To maintain current connection from the CE to the ESI, hydrodynamic flow was superimposed on the CE separation by applying $1.7 \mathrm{kPa}(0.25 \mathrm{psi})$ at the cathodic

reservoir. When the pressure applied to the separation capillary was $>7 \mathrm{kPa}(1 \mathrm{psi})$ the 
analyte migration time varied by at least 25\% (relative standard deviation). This occurred with the BGE adjusted to $\mathrm{pH} 4.5$ as well as 7.0.

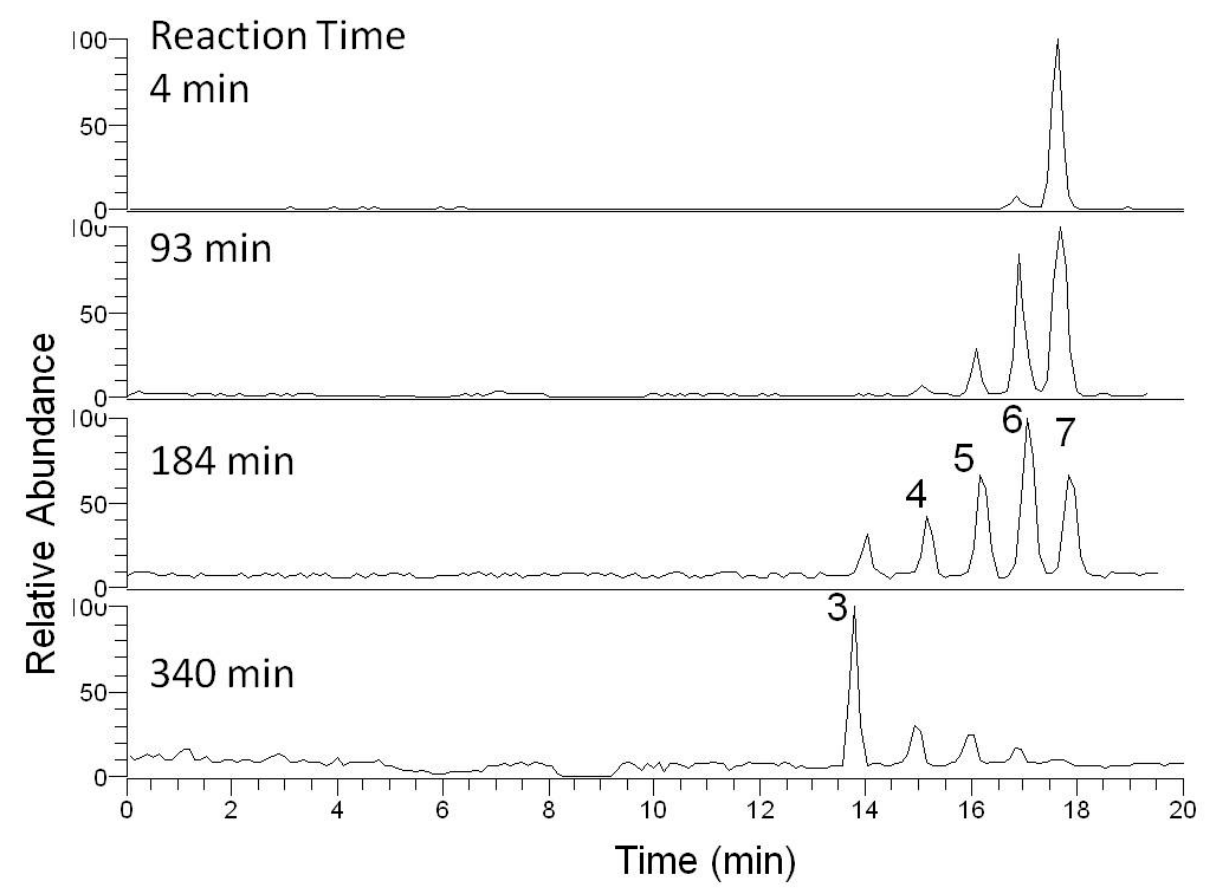

Figure 2-7: $\mathrm{pH}=7.0$ separations of enzymatic digest of maltoheptaose with $\alpha$ amyloglucosidase. Peaks are labeled as follows: maltotriose (3), maltotetraose (4), maltopentaose (5), maltohexaose (6), and maltoheptaose (7).

\subsubsection{Application of Linear Maltooligosaccharides}

The performance of the CE-ESI-MS system was evaluated using linear maltooligosaccharides. First, the position of the CE capillary within the electrospray 
needle and the position of the electrospray needle were optimized using direct infusion of maltoheptaose through the separation capillary in the presence of the coaxial sheath flow. The mass analyzer was set to full scan (ranging from 150 to $2000 \mathrm{Da}$ ) during direct infusion. The maltoheptaose was ionized exclusively with a -2 charge (i.e. $\mathrm{m} / \mathrm{z}=795.77$ Da). This was consistent for the other linear maltooligosaccharides as well. Following optimization, the five maltooligosaccharides were injected and separated with the CEESI-MS system. A typical electropherogram obtained with a semi-permanent phospholipid and reversed polarity separation is shown in Figure 2-8. The maltooligosaccharides differ by only one glucose monomer, yet are easily baseline resolved $\left(\mathrm{R}_{\mathrm{s}} \geq 2.5\right)$ with the pressure-assisted CE separation. The within-day reproducibility $(n=5)$ of migration time obtained for maltooligosaccharide standards was $\leq 1 \%$, and of area was $<6 \%$ (See Table 2-1). 

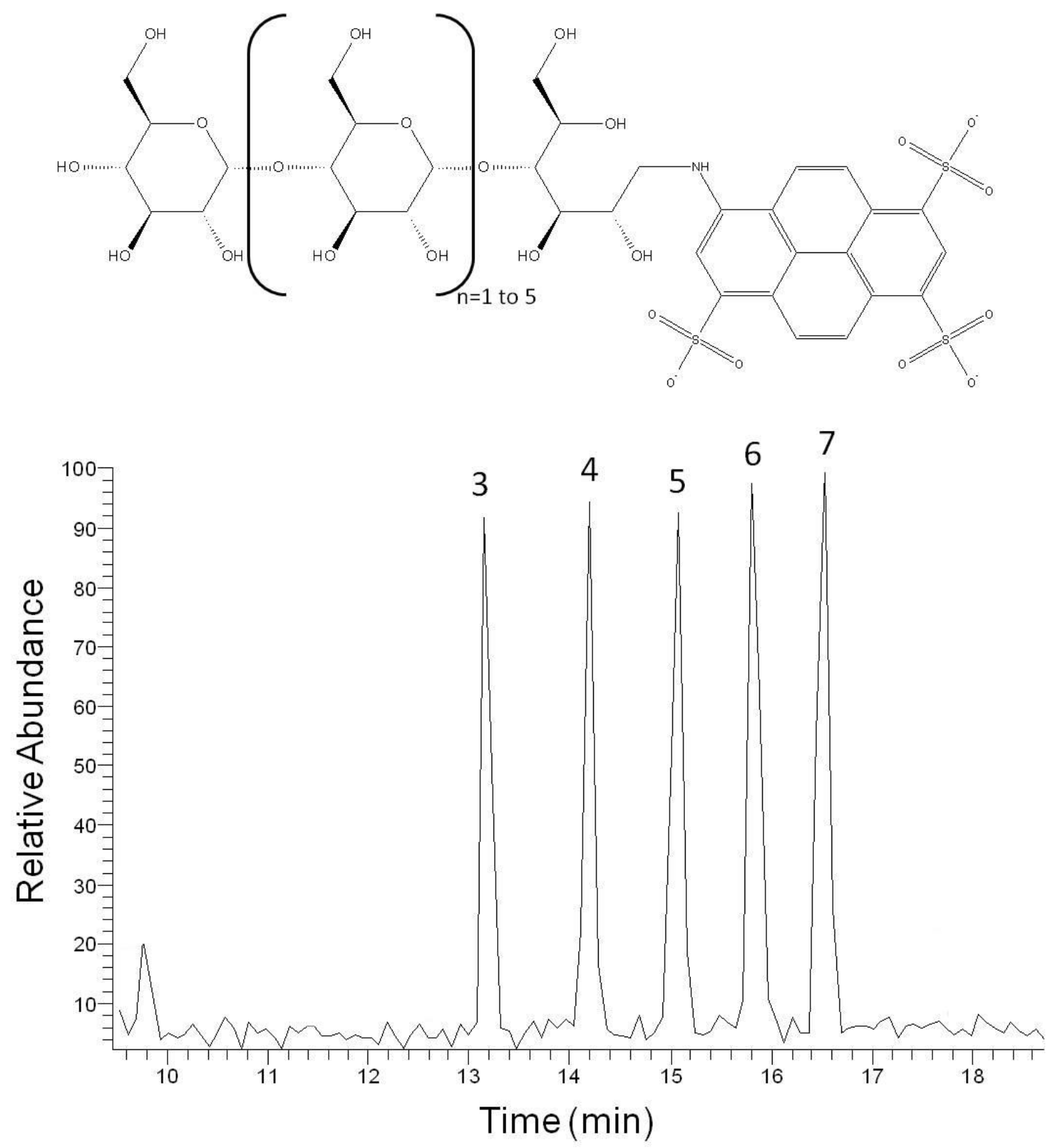

Figure 2-8: The general structure and the electrophoretic separation of APTS-labeled linear maltooligosaccharides. Peaks are labeled as follows: maltotriose (3),maltotetraose (4),maltopentaose (5), maltohexaose (6), and maltoheptaose (7). 
Table 2-1. Figures of Merit Obtained with Linear

Oligosaccharides

\begin{tabular}{|c|c|c|c|c|c|}
\hline Maltooligosaccharide & $\begin{array}{l}\text { Neutral } \\
\text { Molecular } \\
\text { Formula }\end{array}$ & $\begin{array}{l}\text { Observed } \\
\text { Peak m/z }\end{array}$ & $\begin{array}{l}\text { Concentration } \\
\text { in } \mu \mathrm{M}\end{array}$ & $\begin{array}{l}\text { Migration Time } \\
\text { in minutes } \\
(\mathrm{RSD})^{1}\end{array}$ & $\begin{array}{c}\text { Area Count } \\
\times 10^{6} \text { (RSD) }\end{array}$ \\
\hline Triose & $\mathrm{C}_{34} \mathrm{H}_{43} \mathrm{NO}_{24} \mathrm{~S}_{3}$ & 471.8 & 18.2 & $13.1(1 \%)$ & $2.0(5 \%)$ \\
\hline Tetraose & $\mathrm{C}_{40} \mathrm{H}_{53} \mathrm{NO}_{29} \mathrm{~S}_{3}$ & 552.7 & 7.27 & $14.1(1 \%)$ & $2.0(3 \%)$ \\
\hline Pentaose & $\mathrm{C}_{46} \mathrm{H}_{63} \mathrm{NO}_{34} \mathrm{~S}_{3}$ & 633.8 & 9.09 & $15.0(1 \%)$ & $3.0(6 \%)$ \\
\hline Hexaose & $\mathrm{C}_{52} \mathrm{H}_{73} \mathrm{NO}_{39} \mathrm{~S}_{3}$ & 714.8 & 7.27 & 15.7 (1\%) & $2.8(4 \%)$ \\
\hline Heptaose & $\mathrm{C}_{58} \mathrm{H}_{83} \mathrm{NO}_{44} \mathrm{~S}_{3}$ & 795.8 & 6.06 & $16.4(1 \%)$ & $2.8(5 \%)$ \\
\hline
\end{tabular}

${ }^{1}$ relative standard deviation

Sample $(n=5)$ injected for 3 sec at $14 \mathrm{kPa}(2 \mathrm{psi})$. The capillary length was $85.0 \mathrm{~cm}$ and the applied voltage was $253 \mathrm{~V} / \mathrm{cm}$. The cathodic reservoir contained $15 \mathrm{mM}$ ammonium acetate buffered at $\mathrm{pH}=4.5$. The capillary surface was passivated with phospholipid as described in the text. 


\subsubsection{Enzyme Hydrolysis of Linear Maltooligosaccharides}

To show the utility of the method for a sample with varying analyte concentrations, maltoheptaose was incubated with $\alpha$-amyloglucosidase, which is an exoglycosidase enzyme that selectively cleaves the D-mannopyranosyl residues of the maltoheptaose to produce smaller linear oligosaccharides. An enzymatic hydrolysis reaction sampled at 20-minute intervals is shown in Figure 2-9. As the reaction time increases, the peak area for maltoheptaose decreases, while the peak areas of shorter maltooligosaccharides increase.

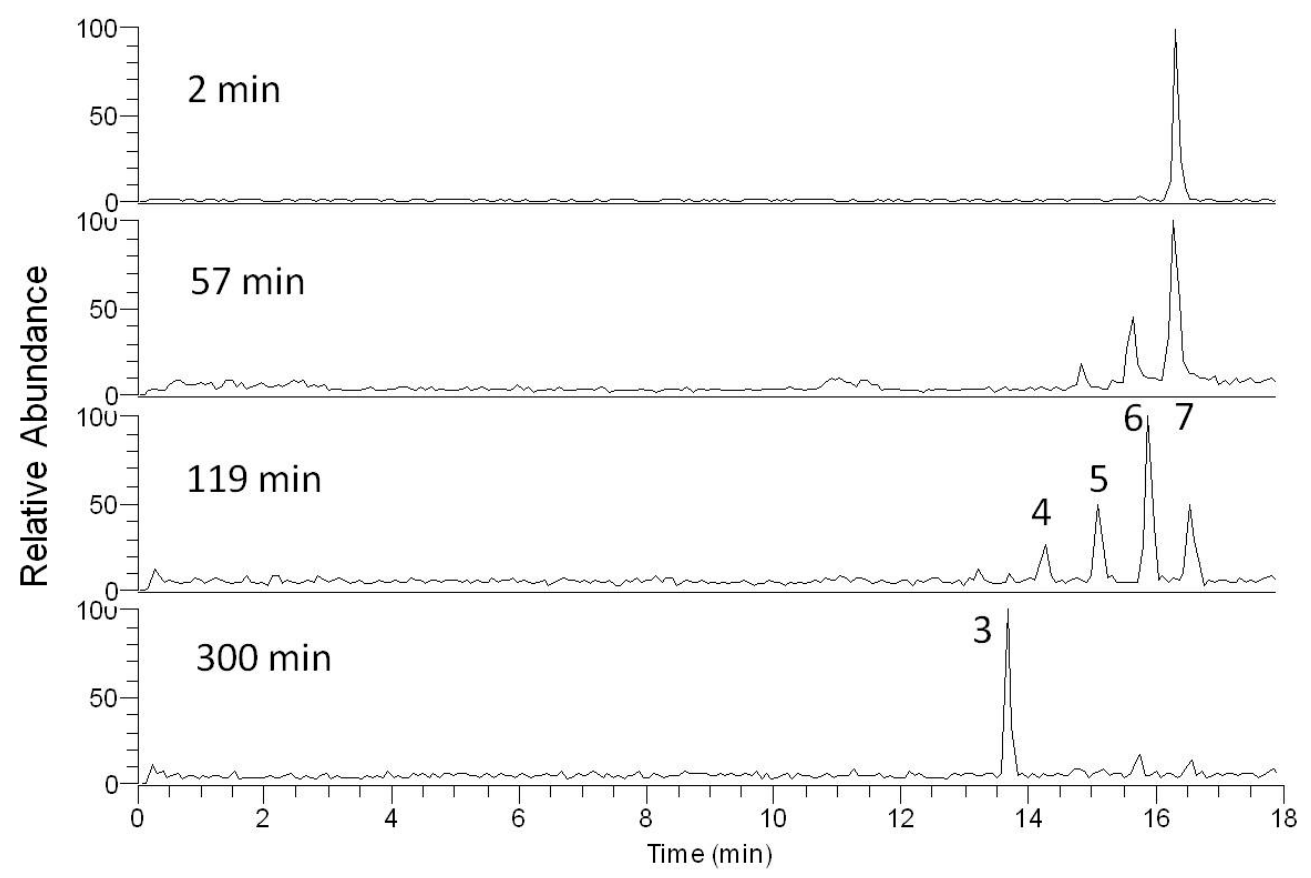

Figure 2-9: Four CE-ESI-MS traces obtained from the enzymatic digest of maltoheptaose with $\alpha$-amyloglucosidase at $\mathrm{pH}=4$.5. Peaks are labeled as follows: maltotriose (3), maltotetraose (4), maltopentaose (5), maltohexaose (6), and maltoheptaose (7). 


\subsubsection{Michaelis-Menten Analysis}

In order to calculate the Michaelis-Menten constant $\alpha$-amyloglucosidase a Michaelis-Menten plot was constructed as described in chapter 1. A pipette volume of $0.2 \mu \mathrm{L}$ of $\alpha$-amyloglucosidase with a reported activity of $0.0001 \mathrm{unit} / \mu \mathrm{L}$ was incubated with $20 \mu \mathrm{L}$ of desalted maltoheptaose at 6 different concentrations (100, 160, 250, 300, 400, and $500 \mu \mathrm{M})$ in order to calculate the Michaelis-Menten constant $\left(\mathrm{K}_{\mathrm{m}}\right)$ for the enzyme-substrate pair. The enzymatic reaction proceeded at $37^{\circ} \mathrm{C}$ in $15 \mathrm{mM}$ ammonium acetate buffered at $\mathrm{pH}$ 4.5. The reaction vial was directly sampled by pressure injection into the CE capillary. Maltotriose formation was observed. In order to determine the initial rate of formation at each concentration of substrate, the maltotriose appearance vs time was plotted. The Michaelis-Menten plot was plotted in Graphpad and yielded a $\mathrm{K}_{\mathrm{m}}=0.3 \pm 0.2 \mathrm{mM}\left(\mathrm{R}^{2}=0.9\right)$, in agreement with the literature[46].

\subsubsection{Fetuin Separations and Identification of Branched Oligosaccharides}

The suitability of the CE-ESI-MS system for the determination of branched oligosaccharides was also determined. Physiologically relevant oligosaccharides are often conjugated to proteins through asparagine residues (N-glycans). These branched Nglycans possess a common core and are more complex than the linear maltooligosaccharides. Commercially available branched glycan standards are more costly than linear oligosaccharides. However, several glycoproteins, such as asialofetuin, are well characterized and are frequently used as a source for glycan standards. Branched 
glycans were enzymatically cleaved from asialofetuin, labeled with APTS, and used to evaluate the performance of phospholipid based CE-ESI-MS separations. Two predominant triantennary glycans are derived from asialofetuin AII and FII (See Figure 2-10 for structures). The FII and AII glycans are comprised of the same saccharide monomers, but differ only in the linkage of the terminal galactose in the middle antenna; FII is a $\beta 1,3$-linkage, while AII is a $\beta 1$, 4-linkage. Using direct infusion through the coaxial sheath flow, the AI, AII, and FII branched glycans were observed only with a -3 charge state using full scan. The AI glycan, detected as $693.06 \mathrm{~m} / \mathrm{z}$, is resolved from the AII/FII pair by CE). The AII/FII branched glycans observed as m/z=814.73 Da, have the same mass-to-charge ratio.

\subsubsection{Separation of AII from FII}

As shown in the CE separation in trace A of Figure 2-10, AII and FII glycans are indistinguishable by both the CE and MS. Enzymes have been utilized in conjunction with mass spectrometric analyses to establish structural linkages. Many exoglycosidase enzymes are commercially available that cleave the terminal oligosaccharides on the nonreducing end of the glycan. For example, $\beta 1-4$ galactosidase cleaves only the $\beta 1-4$ linkages of D-galactopyranosyl residues. The labeled AII from FII were incubated with $\beta 1-4$ galactosidase. While all three terminal galactopyranosyl residues are removed from AII, only two galactopyranosyl residues are cleaved from FII, and the $\beta 1-3$ linked galactopyranosyl residue remains. As shown in trace B of Figure 2-10, the AII and FII 
products are baseline resolved and detected as -3 ions at $652.73 \mathrm{~m} / \mathrm{z}$ and $706.69 \mathrm{~m} / \mathrm{z}$, respectively.

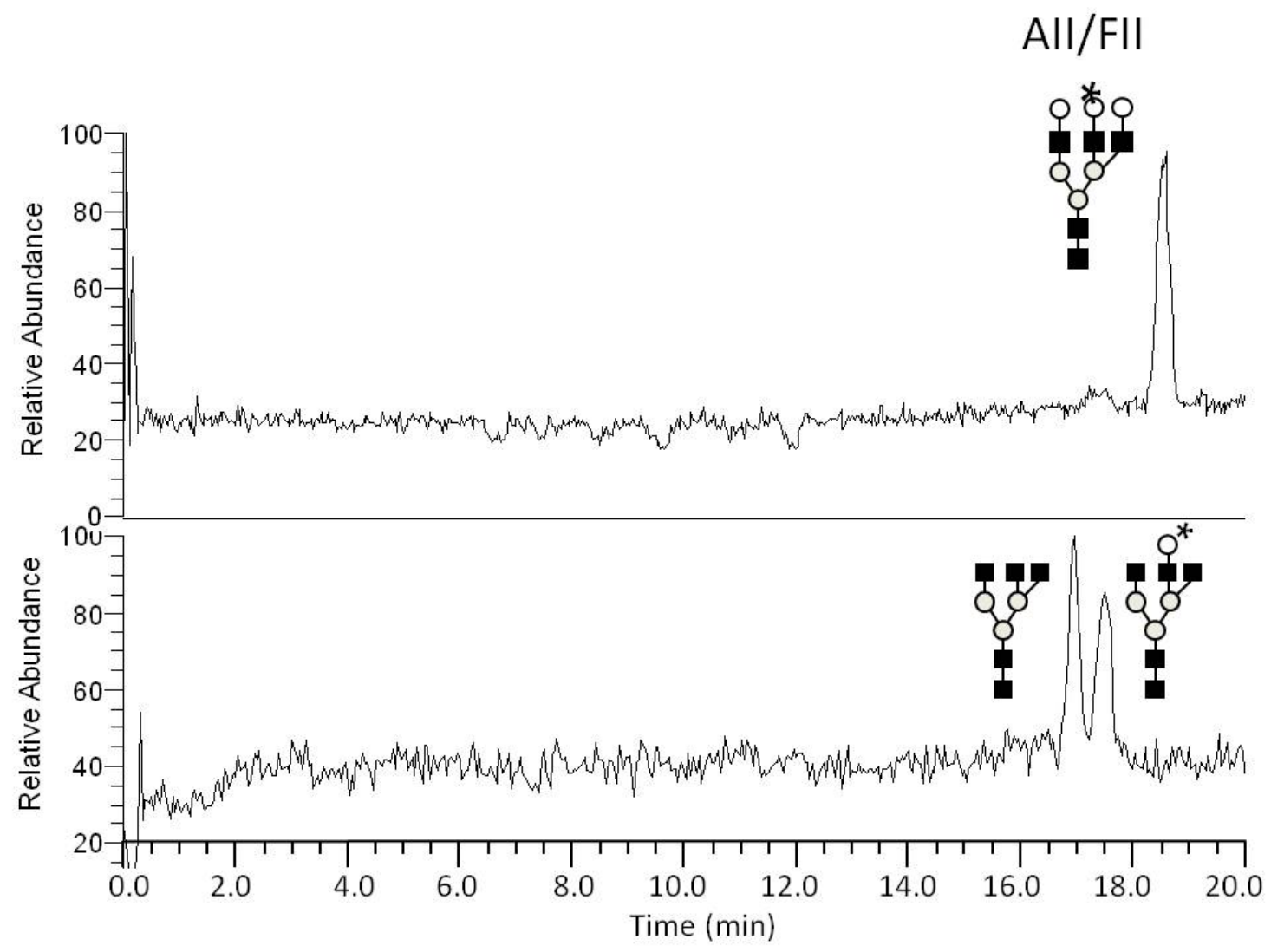

Figure 2-10: Trace A is an electropherogram of the AII/FII pair of branched isomeric oligosaccharides. The peaks comigrate and are indistinguishable at $\mathrm{m} / \mathrm{z}$ of 814.73 by the MS. Trace B is an electropherogram of the two different fragments resulting from incubation with $\beta 1-4$ galactosidase. 


\subsection{Conclusions}

This research demonstrates the use of a semi-permanent phospholipid coating for the suppression of electroosmotic flow in pressure-assisted capillary electrophoresis that has been successfully integrated with a coaxial sheath flow interface for electrospray

ionization in negative mode. Individual control of the separation current and electrospray current was facilitated by placing a resistor in parallel with the electrospray. This design enables the first use of a semi-permanent phospholipid coating with electrospray ionization. The utility of the method was demonstrated with successful separation of linear oligosaccharides and used to monitor the enzymatic hydrolysis of maltooligosaccharides with $\alpha$-amyloglucosidase. The $\mathrm{Km}$ for $\alpha$-amyloglucosidase with maltoheptaose was then calculated. Branched oligosaccharides were separated and detected with the system. The enzyme $\beta 1-4$ galactosidase was used to distinguish branched isomeric oligosaccharides derived from asialofetuin. The technique offers flexibility in identification of linear and branched oligosaccharides labeled with APTS based migration as well as the mass-to-charge ratio. The method benefits from a low sample consumption and was able to monitor reactions of $20 \mu \mathrm{L}$. 


\subsection{Future Directions}

This work has the potential for future research in various areas. First, the limits of detection can be improved by integration of a nanospray source and by integration with detection based on laser-induced fluorescence. Secondly, future efforts can involve miniaturization of the separation system and automation. Automation could be achieved by construction of a new electrospray source that could accept a $360 \mu \mathrm{m}$ outer diameter capillary and enable motorized positioning of the source for flushes. $360 \mu \mathrm{m}$ outer diameter capillary is the standard capillary outer diameter for automated Beckman capillary electrophoresis instruments. Further efforts can be utilized to continue the pursuit of a coupling scheme to link a Q2.5 5\% phospholipid-filled capillary to the electrospray source in order to have the ability to separate and distinguish branched, isomeric oligosaccharides without enzymatic digestion.

\subsubsection{Sheathless Interfaces}

In order to find a viable system for coupling CE to MS and to enable introduction of phospholipids to the separation without adversely affecting the ionization, several different coupling schemes were attempted. The coupling schemes took several stages and involved multiple homebuilt interfaces. This section is intended as a brief overview of the CE-MS coupling schemes attempted prior to the final selection of coaxial sheath flow interface. These interfaces displayed unique advantages that could be utilized for 
improving the existing design of the system. Sheathless interfaces have less dilution of the analyte, therefore the interfaces will be able to have a lower limit of detection.

\subsubsection{CE Fracture Capillary Interface}

A fracture capillary joint was shown as an effective setup for decoupling the current of the capillary electrophoresis and the currents monitored by electrochemical detection[47]. A fracture capillary interface similarly can be used to decouple the current of capillary electrophoresis and the current of the electrospray. Similar to the liquid junction interface, the fracture capillary interface enables the second electrical contact before the electrospray in a buffer well. The constructed fracture capillary interface was capable of performing pressure-assisted capillary electrophoresis. However, the fracture required extremely delicate construction. 

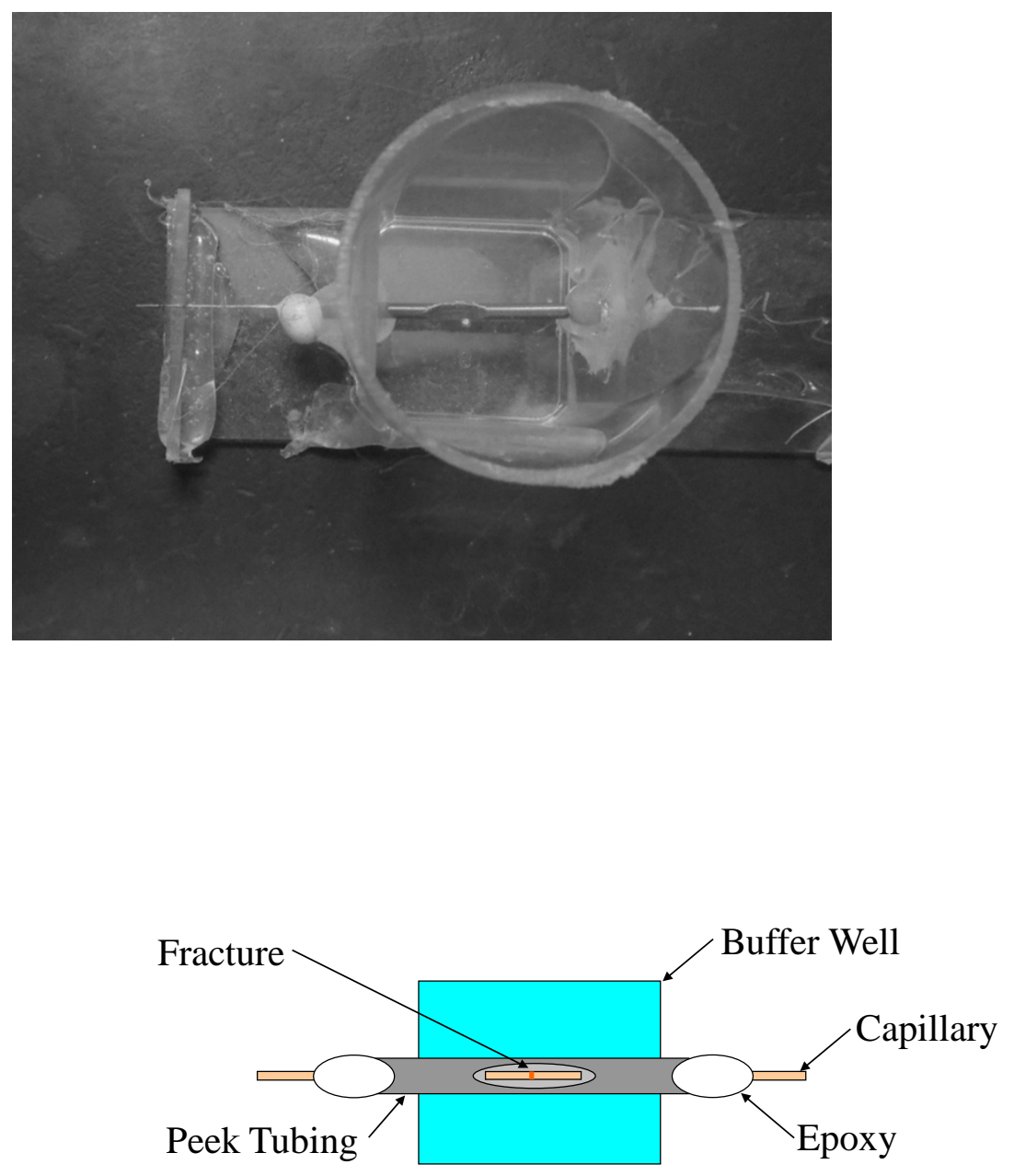

Figure 2-11: Fracture capillary sheathless interface 


\subsubsection{Microfluidic Chip Interfaces}

Microfluidic chips offer miniaturization and mass production benefits. Chip designs have the potential of eliminating the requirement of precise capillary placement and offer a simple nanospray coupling.

The microfluidic chip with a conventional double $\mathrm{T}$ with four ports was the first design for the purpose of utilizing Q 2.5 5\% phospholipid additives in the separation with electrospray. One port was connected to the separation capillary, another was connected to the electrospray source, and the other two ports were connected to syringe pumps for the makeup flow needed to maintain the electrospray. This design was an attempt to use the viscosity of the phospholipids to direct the makeup flows, applied at two ports of the microfluidic chip, towards the port connected to the electrospray capillary. Ultimately, the flow rates required for stable electrospray caused the pushback of the phospholipids which could not resist the pressure applied by the makeup flows. The phospholipids could be observed backing out of the capillary into the buffer well during the separation, and the analytes were never detected reaching the ion source. 

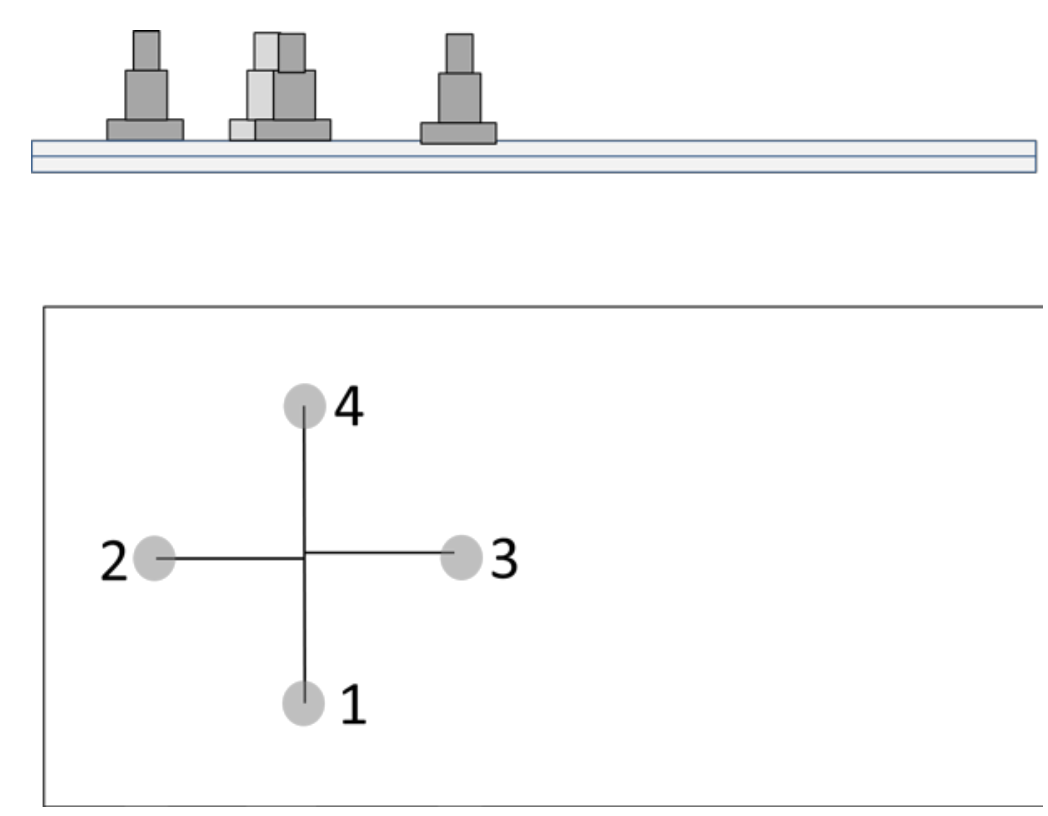

Figure 2-12: Simple double T microfluidic chip

In order to deal with the pushback of the separation channel in the double $\mathrm{T}$, a new, more complex microfluidic chip was designed. This chip introduced the use of a hydrodynamic restrictor[48] to prevent pushback of the separation. This chip also integrated the separation channel on the chip in order to enable better temperature regulation with thermoelectric modules. Several designs of the chip were tested. On a microscope, the design chip was shown to be capable of balancing the makeup flows' pressure, preventing the pushback, and maintaining the separation while electrospray was spraying to a grounded metal plate. The next experimental step is to successfully utilize the separation with the electrospray on the mass spectrometer. There are some challenges that still need overcome with the current design. The hydrodynamic restrictor is prone to boiling the solvent and is a source of plugging, since it is the smallest feature in the chip. Microfluidic designs for coupling will negate the need for fine positioning in the 
interface, enable the use of the nanospray ion source, and add the benefit of having a disposable chip.
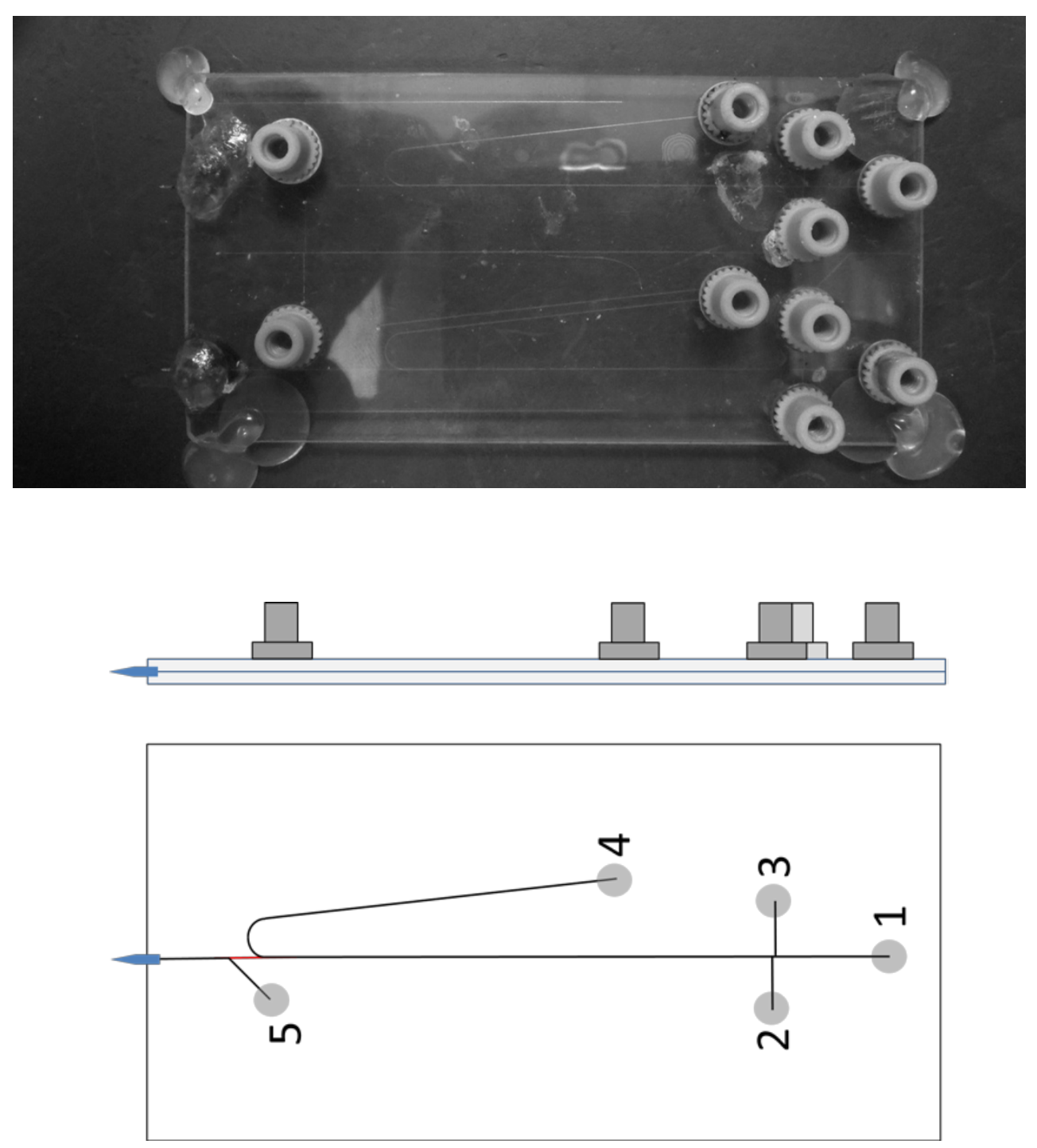

Figure 2-13: More complex microfluidic chip with integrated hydrodynamic restrictor and nanospray ion source 


\subsection{Bibliography}

[1] Langan, T. J., Holland, L. A., Electrophoresis Accepted November 5, 2011.

[2] Yamashita, M., Fenn, J. B., The Journal of Physical Chemistry. 1984, 88, 4671-4675.

[3] Haselberg, R., de Jong, G. J., Somsen, G. W., Electrophoresis 2011, 32, 66-82.

[4] Campa, C., Coslovi, A., Flamigni, A., Rossi, M., Electrophoresis 2006, 27, 20272050.

[5] Kebarle, P., Ho, Y., in: Cole, R. B. (Ed.), Electrospray ionization mass spectrometry : fundamentals, instrumentation, and applications, Wiley, New York 1997, pp. 3-65.

[6] Juraschek, R., Röllgen, F. W., International Journal of Mass Spectrometry 1998, 177, $1-15$.

[7] Nemes, P., Marginean, I., Vertes, A., Analytical Chemistry. 2007, 79, 3105-3116.

[8] Tang, K., Gomez, A., Phys. Fluids 1994, 6, 2317-2332.

[9] Dole, M., Mack, L. L., Hines, R. L., Mobley, R. C., et al., J. Chem. Phys. 1968, 49, 2240-2249.

[10] Kebarle, P., Tang, L., Analytical Chemistry. 1993, 65, 972A-986A.

[11] Iribarne, J. V., Thomson, B. A., J. Chem. Phys. 1976, 64, 2287-2294.

[12] Ruhaak, L., Zauner, G., Huhn, C., Bruggink, C., et al., Analytical and Bioanalytical Chemistry, Springer Berlin / Heidelberg 2010, pp. 3457-3481.

[13] Elhamili, A., Wetterhall, M., Sjödin, M., Sebastiano, R., Bergquist, J., Electrophoresis 2010, 31, 1151-1156.

[14] Olmo, S., Gotti, R., Naldi, M., Andrisano, V., et al., Analytical and Bioanalytical Chemistry, Springer Berlin / Heidelberg 2008, pp. 1881-1888. 
[15] Sanz-Nebot, V., Balaguer, E., Benavente, F., Neusüß, C., Barbosa, J., Electrophoresis S 2007, 28, 1949-1957.

[16] Melanson, J. E., Baryla, N. E., Lucy, C. A., Analytical Chemistry. 2000, 72, 41104114.

[17] Cunliffe, J. M., Baryla, N. E., Lucy, C. A., Analytical Chemistry. 2002, 74, 776-783.

[18] White, C. M., Luo, R., Archer-Hartmann, S. A., Holland, L. A., Electrophoresis 2007, 28, 3049-3055.

[19] Gulcev, M. D., McGinitie, T. M., Bahnasy, M. F., Lucy, C. A., Analyst 2010, 135.

[20] McComb, M. E., Perreault, H., Electrophoresis 2000, 21, 1354-1362.

[21] Somsen, G. W., Mol, R., de Jong, G. J., Journal of Chromatography A 2003, 1000, 953-961.

[22] Eriksson, J. H. C., Mol, R., Somsen, G. W., Hinrichs, W. L. J., et al., Electrophoresis 2004, 25, 43-49.

[23] Smith, R. D., Barinaga, C. J., Udseth, H. R., Analytical Chemistry. 1988, 60, 19481952.

[24] Lee, E. D., Mück, W., Henion, J. D., Covey, T. R., Biol. Mass Spectrom. 1989, 18, 844-850.

[25] Issaq, H. J., Janini, G. M., Chan, K. C., Veenstra, T. D., Journal of Chromatography A 2004, 1053, 37-42.

[26] Smith, R. D., Olivares, J. A., Nguyen, N. T., Udseth, H. R., Analytical Chemistry. 1988, 60, 436-441.

[27] Wetterhall, M., Nilsson, S., Markides, K. E., Bergquist, J., Analytical Chemistry. 2001, 74, 239-245. 
[28] Cao, P., Moini, M., Journal of The American Society for Mass Spectrometry, Springer New York 1997, pp. 561-564.

[29] Fang, L., Zhang, R., Williams, E. R., Zare, R. N., Analytical Chemistry. 1994, 66, 3696-3701.

[30] Mazereeuw, M., Hofte, A. J. P., Tjaden, U. R., van der Greef, J., Rapid Commun. Mass Spectrom. 1997, 11, 981-986.

[31] Janini, G. M., Zhou, M., Yu, L.-R., Blonder, J., et al., Analytical Chemistry. 2003, 75, 5984-5993.

[32] Severs, J. C., Smith, R. D., Analytical Chemistry. 1997, 69, 2154-2158.

[33] Tong, W., Link, A., Eng, J. K., Yates, J. R., Analytical Chemistry. 1999, 71, 2270 2278.

[34] Luo, R., Archer-Hartmann, S. A., Holland, L. A., Analytical Chemistry. 2010, 82, 1228-1233.

[35] Duteil, S., Gareil, P., Girault, S., Mallet, A., et al., Rapid Commun. Mass Spectrom. 1999, 13, 1889-1898.

[36] Sandra, K., Van Beeumen, J., Stals, I., Sandra, P., et al., Analytical Chemistry 2004, 76, 5878-5886.

[37] Ismaiel, O. A., Halquist, M. S., Elmamly, M. Y., Shalaby, A., Thomas Karnes, H., Journal of Chromatography B 2008, 875, 333-343.

[38] Joucla, G., Brando, T., Remaud-Simeon, M., Monsan, P., Puzo, G., Electrophoresis 2004, 25, 861-869.

[39] Che, F.-Y., Song, J.-F., Zeng, R., Wang, K.-Y., Xia, Q.-C., Journal of Chromatography A 1999, 858, 229-238. 
[40] Szabo, Z., Guttman, A., Rejtar, T., Karger, B. L., Electrophoresis 2010, 31, 13891395.

[41] Charlwood, J., Birrell, H., Gribble, A., Burdes, V., et al., Analytical Chemistry. 2000, 72, 1453-1461.

[42] Ongay, S., Neusüß, C., Analytical and Bioanalytical Chemistry, Springer Berlin / Heidelberg 2010, pp. 845-855.

[43] Kabel, M. A., Heijnis, W. H., Bakx, E. J., Kuijpers, R., et al., Journal of Chromatography A 2006, 1137, 119-126.

[44] Larsson, M., Sundberg, R., Folestad, S., Journal of Chromatography A 2001, 934, 75-85.

[45] Williams, B. A., Vigh, G., Analytical Chemistry. 1996, 68, 1174-1180.

[46] Abe, J., Nagano, H., Hizukuri, S., J. Appl. Biochem. 1985, 7, 235-247.

[47] Zhang, S. S., Liu, H. X., Wu, Y. J., Yu, C. L., Analyst 2001, 126.

[48] Razunguzwa, T. T., Lenke, J., Timperman, A. T., Lab Chip 2005, 5. 


\section{CHAPTER 3:}

Using pH-Mediated Sample Stacking with Micellar Electrokinetic Capillary

Chromatography for the Assessment of Aptamer-Steroid Binding 


\subsection{Introduction}

The work presented here details the use of capillary electrophoresis to measure the binding affinity of $17 \beta$-estradiol with an immobilized DNA aptamer and has been published in a peer-reviewed journal[1]. For this project, pH-mediated sample stacking was used to inject estradiol into the separation capillary that was recovered from the immobilized DNA aptamer. The goal of this work was primarily to study the binding affinity of the immobilized DNA aptamer to $17 \beta$-estradiol. Consequently, the longterm/future goal was to use the immobilized DNA aptamer to study steroid levels in fish plasma. The success of this strategy is based on molecular recognition.

\subsubsection{Recognition Elements}

Recognition elements can be used to selectively collect steroids from blood samples. Conventionally, antibodies have been utilized to assay steroids. However, other recognition elements such as molecular imprinted polymers and aptamers can also be used. The recognition elements each have their own advantages and drawbacks.

Antibodies are often used as selection agents for steroidal compounds and have been utilized to quantify steroids in capillary separations via competitive binding[2]. A major disadvantage for antibody assays is that they can quantify only a single target. Assays for multiple steroids require additional reagents, biological sample, labor, and antibodies. As a second disadvantage, not all antibodies are commercially available for 
different steroids. Furthermore, even though developing antibodies in-house is possible, the procedure is quite tedious.

Molecular imprinted polymers are an alternative to generating antibodies specific for steroids. In order to generate a molecular imprinted polymer, the targeted compound is combined with the functional monomer and then polymerized[3, 4]. Cavities are formed around the target in the polymer. Once the steroid template has been removed, the cavities serve as artificial binding pockets. However, the amount of molecularly imprinted material that can be generated is limited by the amount of steroid template available; thus commercialization and mass production are limited.

\subsubsection{Aptamers}

Molecular recognition elements, also called aptamers, are functional nucleic acids that form secondary and tertiary structures with the potential to bind target molecules[5]. The tertiary structure attributed to binding is thermally reversible. At temperatures of $95{ }^{\circ} \mathrm{C}$, the hydrogen bonds that support secondary structure melt. This provides a convenient method to release the target once it has been captured by the aptamer. The nucleic acid sequence can be modified with different functional groups and covalently immobilized. The main advantage of aptamers over molecular imprinted polymers and antibodies is that nucleic acids are easily replicated by PCR amplification. 
The generation and design of aptamers has been advanced using a process of systematic evolution of ligands by exponential enrichment[6]. In this method, a combinatorial mixture of single-stranded DNA is incubated with the target using specific binding conditions (solvent, ionic strength, $\mathrm{pH}$ ). When DNA binds to the target, the DNA-target complexes are isolated, and the DNA sequence amplified. The process of selection and amplification is repeated, and the resultant aptamers that bind to the target are identified and optimized at a much faster pace than would occur under natural selection.

Aptamers with selectivity for steroidal compounds offer new advances in sensing steroidal compounds. Recently, Kim et al. discovered an aptamer selective for $17 \beta$ estradiol[7]. The affinity of the reported sequence to estradiol and selection over other compounds has been demonstrated[7-10]. The selectivity of the aptamer was tested against three characterized ligands, two nonbinding and one with a binding affinity (trans-diethylstilbestrol)[9]. The amount of diethylstilbestrol recovered was five-fold lower than that obtained with estradiol. This aptamer was also incorporated as the working element in electrochemical sensors of $17 \beta$-estradiol[7, 8, 10]. Two different groups have reported a different dissociation constant for this 76 base aptamer with $17 \beta$ estradiol[ $[7,9]$. The linkage chemistry for the aptamer to the surface of the bead or sensor may affect the binding affinity of $17 \beta$-estradiol. The actual binding affinity for each experimental system may vary. Therefore, measuring this value is useful to further integrate and apply the aptamer for sensing and selection. 


\subsubsection{Separation Mechanism}

Capillary electrophoresis is an effective microscale method to measure or screen binding affinity[11]. CE separations have been reported in automated instruments as well as microfluidic devices that profile and quantify multiple steroidal compounds in a single run[12-22]. Steroidal compounds are generally neutral and hydrophobic, and different combinations of additives are used to accomplish these separations. Most of these CE methods utilize UV-visible absorbance detection. Sweeping and stacking have been integrated in CE to improve the detection limits achievable with absorbance detection[12, $13,15]$.

The separation mechanism in this study is depicted in Figure 3-1 and utilizes pHmediated sample stacking followed by separation with secondary equilibria. The method has been reported for the separation of up to eight different steroids in 4 minutes[13]. Sample introduction with $\mathrm{pH}$-mediated stacking provides nanomolar detection limits with conventional UV-visible absorbance detection[12]. In pH-mediated sample stacking[12, 13], the steroidal compounds form a guest-host complex with carboxymethyl- $\beta$ cyclodextrin. The complex is charged at $\mathrm{pH} 10$ in the sample vial, thus can be electrokinetically injected. Once introduced into the $\mathrm{pH} 2.5$ separation buffer of the capillary, the carboxymethyl- $\beta$-cyclodextrin changes from negatively charged to neutral and stacks at the $\mathrm{pH}$ interface. Following stacking, multiple steroidal compounds are separated using secondary equilibria between the sodium dodecyl sulfate (SDS) micelles and hydroxypropyl- $\beta$-cyclodextrin. The micelles migrate toward the detection window 
under reversed polarity; and the hydroxypropyl- $\beta$-cyclodextrins, being neutral, are effectively immobile in the acidic background electrolyte. 
A)

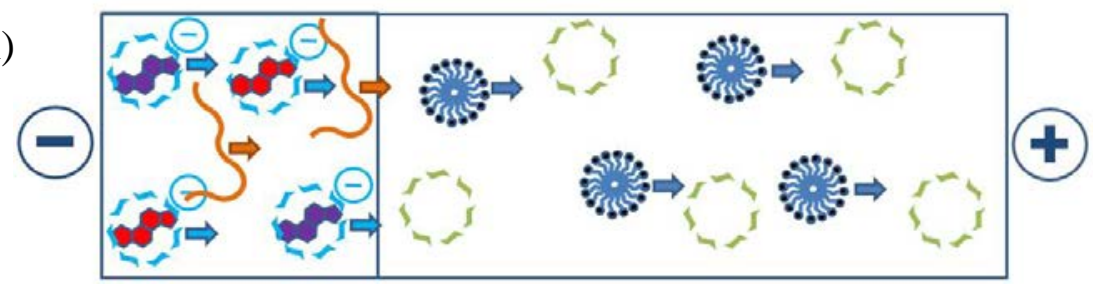

B)

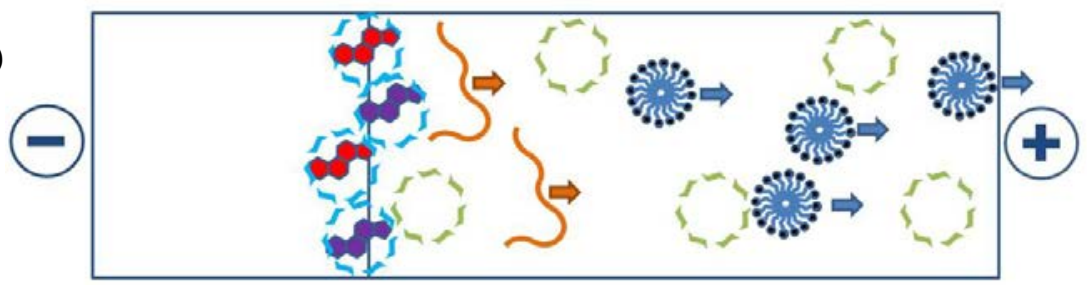

C)

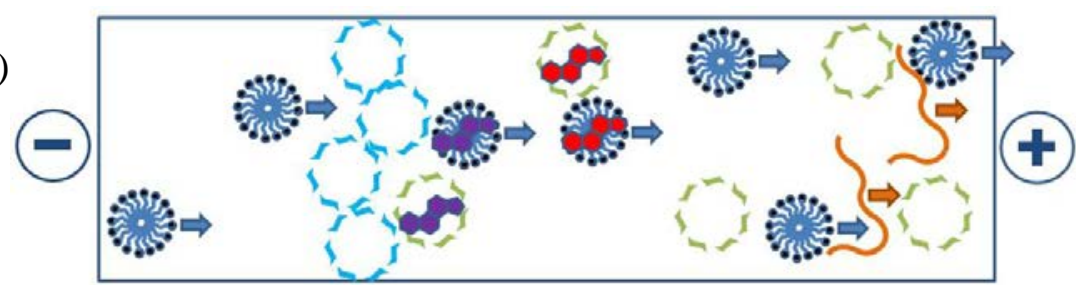

D)

E)

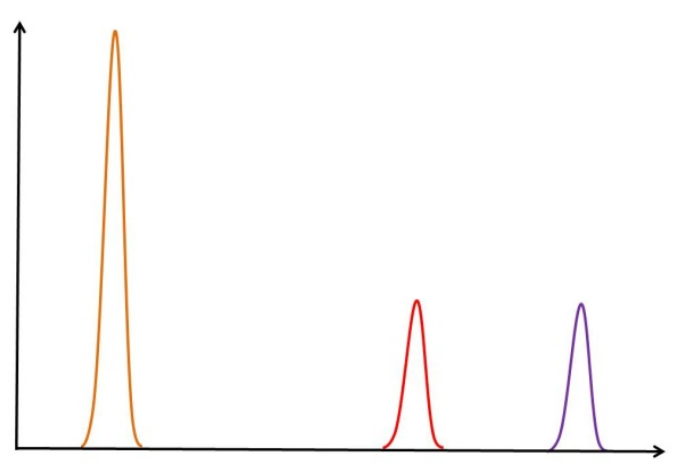

Time

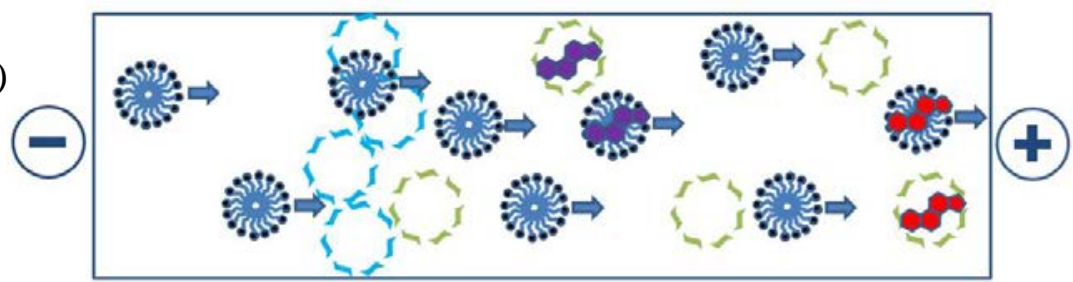

Key
$\begin{aligned} & \text { Unfolded Aptamer } \\ & \text { (negatively charged) }\end{aligned}$
$\begin{aligned} & \text { SDS (negatively } \\ & \text { charged) }\end{aligned}$
HPCD (neutral)
CMCD (negatively
CMCD (neutral)

Figure 3-1: Separation mechanism: A) and B) sample stacking, C) and D) separation, and E) expected electropherogram 


\subsection{Materials and Methods}

\subsubsection{Chemicals}

The biotinylated DNA aptamer was synthesized by IDT (Coralville, IO, USA). Sodium hydroxide, sodium chloride, potassium chloride, sodium dodecyl sulfate (SDS), carboxymethyl- $\beta$-cyclodextrin, testosterone, and 3-[cyclohexylamino]-1-propanesulfonic acid (CAPS) were purchased from Sigma-Aldrich (St. Louis, MO, USA). Streptavidinmodified magnetic beads (S1420S) were purchased from New England BioLabs (Ipswich, MA, USA). Methanol was purchased from EMD Biosciences (La Jolla, CA, USA). 17 $\beta$-estradiol and estrone were purchased from Steraloids, Inc. (Newport, RI, USA). 17 $\alpha$-ethynyl estradiol was purchased from Cayman Chemical (Ann Arbor, MI, USA). The deoxyribonucleotide triphosphates were purchased from Omega Bio-Tek (Norcross, GA, USA). Hydroxypropyl- $\beta$-cyclodextrin (HPCD) was purchased from VWR (West Chester, PA, USA). Hydrochloric acid, magnesium chloride, and sodium phosphate monobasic salt were purchased from Fisher Scientific (Fair Lawn, NJ, USA). Tris hydrochloride was purchased from Mallinckrodt Maker Inc. (Phillipsburg, NJ,

USA). Deionized water was obtained from an Elga Purelab ultra water system (Lowell, MA). 


\subsubsection{Instrumentation}

Separations were performed using a Beckman Coulter P/ACE MDQ capillary electrophoresis instrument (Beckman Coulter, Fullerton, CA, USA) shown in Figure 3-2. The P/ACE MDQ was equipped with a photodiode array (PDA) for UV-visible absorbance detection which provided simultaneous determination of steroids at multiple wavelengths of 200, 225, 254 nm. A dry bath (Fisher Scientific, Fair Lawn, NJ, USA) was used in sample preparation for incubation for biotin-streptavidin release. Centrifugation was performed on a picofuge (Stratagene, La Jolla, CA, USA)
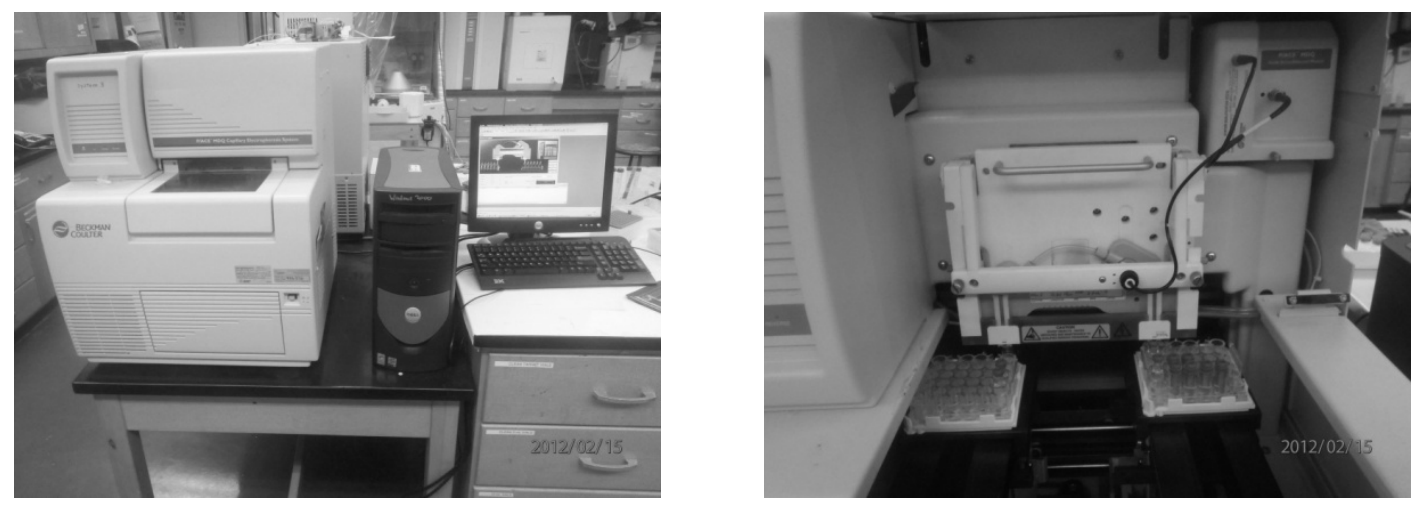

Figure 3-2: Beckman Coulter P/ACE MDQ capillary electrophoresis instrument 


\subsubsection{Capillary Electrophoresis}

Initially, the $25 \mu \mathrm{m}$ inner diameter, $360 \mu \mathrm{m}$ outer diameter, $30 \mathrm{~cm}$ long fused silica separation capillary (Polymicro Technologies, LLC, Phoenix, AZ, USA) with the detection window positioned $10.2 \mathrm{~cm}$ (short end separation) from the cathodic reservoir was initially flushed at $170 \mathrm{kPa}$ at the cathodic reservoir with $1.0 \mathrm{M}$ sodium hydroxide for 60 minutes. Each morning the capillary was flushed at $170 \mathrm{kPa}$ at the cathodic reservoir with 1.0 M sodium hydroxide (30 min), deionized water (5 min), 1.0 M hydrochloric acid (25 min), deionized water (5 min), and followed by the background electrolyte (30 min). The background electrolyte is comprised of $30 \mathrm{mM}$ SDS, $13 \mathrm{mM}$ hydroxypropyl- $\beta$-cyclodextrin, and $200 \mathrm{mM}$ sodium phosphate, buffered at $\mathrm{pH} 2.5$. The background electrolyte is made daily by dissolving SDS in sodium phosphate buffer followed by sequentially dissolving the hydroxypropyl- $\beta$-cyclodextrin. At the end of each day the capillary is flushed with $170 \mathrm{kPa}$ at the cathodic reservoir with $1.0 \mathrm{M}$ sodium hydroxide (40 min) and then with deionized water (10 min). The capillary is then stored in deionized water until the next use.

\subsubsection{Sample Preparation}

Stacking and MEKC separation are used to measure the dissociation constant of the immobilized 76 base pair aptamer as outlined in Figure 3-3. The DNA aptamer (GCT TCC AGC TTA TTG AAT TAC ACG CAG AGG GTA GCG GCT CTG CGC ATT CAA TTG CTG CGC GCT GAA GCG CGG AAG C) was synthesized with a biotin 
connected to the 5' base via a 15 atom spacer arm (tetra-ethyleneglycol). The aptamer was reconstituted at a concentration of $10 \mu \mathrm{M}$ in a binding buffer similar to that previously reported[2] (200 mM NaCl, $10 \mathrm{mM} \mathrm{MgCl} 2,25 \mathrm{mM}, \mathrm{KCl}$, 5\% ethanol, 100 $\mathrm{mM}$ Tris- $\mathrm{HCl}$ buffered at $\mathrm{pH}$ 8) and unfolded via heating at $95^{\circ} \mathrm{C}$ for 10 minutes. The solution was then incubated with $17 \beta$-estradiol at $25^{\circ} \mathrm{C}$ for 60 minutes. The biotinylated aptamer was coupled to $40 \mu \mathrm{L}$ of streptavidin-modified magnetic beads provided at a concentration of $4 \mathrm{mg} / \mathrm{mL}$. An approximate binding capacity of 500 picomoles of singlestranded 20 base pair biotinylated oligonucleotide per mg of bead was reported by the manufacturer. Thus, these beads can bind a maximum DNA concentration of $\sim 2 \mu \mathrm{M}$ (80 picomoles). To prevent nonspecific interaction between the beads and steroidal compounds, the magnetic beads were incubated with $10 \mathrm{mM}$ deoxyribonucleotide triphosphates. The aptamer-estradiol complex was combined with the magnetic beads and allowed to incubate for 60 minutes for the immobilization of the aptamer-complex via the biotin-streptavidin interaction. After incubation, the beads were rinsed with the binding buffer to remove any unbound estradiol and DNA. A magnet was used to separate the beads from solution when liquid was removed. The estradiol bound to the immobilized aptamer remained on the magnetic beads during this rinse. After flushing, the magnetic beads were reconstituted in the stacking buffer, which is comprised of 1.0 $\mathrm{mM}$ carboxymethyl- $\beta$-cyclodextrin and $50 \mathrm{mM}$ CAPS buffered at $\mathrm{pH} 10$. To release the DNA aptamer bound to the bead, the beads were heated to $70^{\circ} \mathrm{C}$. The biotin-streptavidin interaction is reportedly dissociated without degrading streptavidin protein at this temperature[23]. As the biotinylated beads were dissociated effectively in deionized water or stacking buffer, further dissociation was accomplished in stacking buffer to 
simplify sample preparation. The final solution removed from the beads was placed and stored in the back tray of the Beckman at $25^{\circ} \mathrm{C}$. 


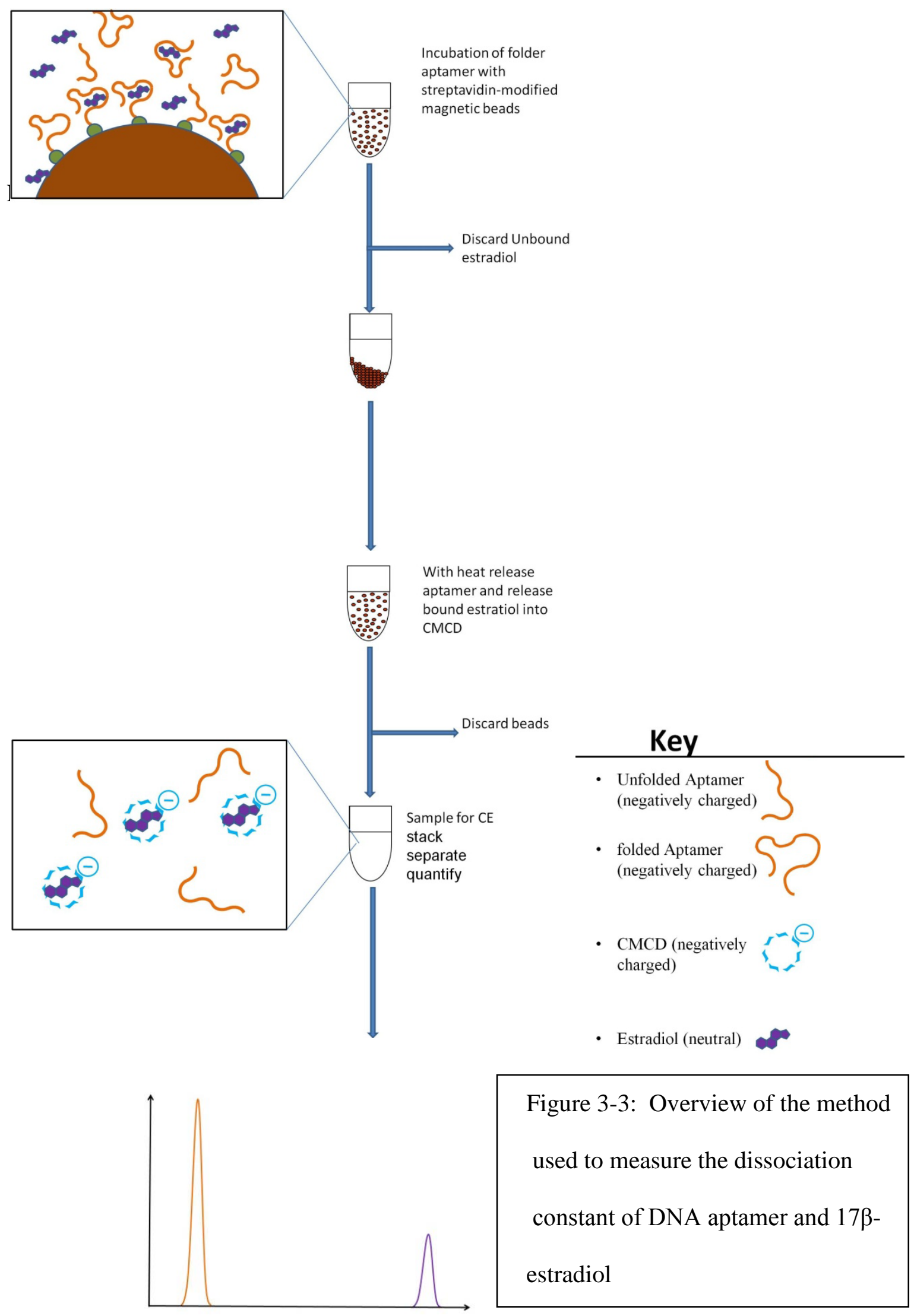




\subsubsection{Separation Conditions}

The final solution removed from the beads contained both estradiol and DNA. These samples were injected into the separation capillary using the method of sample stacking previously reported[12, 13]. The capillary was maintained at $25^{\circ} \mathrm{C}$ for all runs. Each run began with a 2 minute, $140 \mathrm{kPa}$ (20psi) flush of the background electrolyte from the anodic reservoir to help prevent plugging of the capillary. A plug of deionized water was injected at $14 \mathrm{kPa}(2 \mathrm{psi})$ for 6 seconds. The sample was then stacked by electrokinetically injecting the sample for 60 seconds at $10 \mathrm{kV}$. Following stacking, the estradiol and DNA were separated in the background electrolyte comprised of $30 \mathrm{mM}$ SDS, 13 mM hydroxypropyl- $\beta$-cyclodextrin, and $200 \mathrm{mM}$ sodium phosphate, buffered at $\mathrm{pH}$ 2.5. This separation is accomplished under reverse polarity with $16 \mathrm{kV}$ applied potential. $200 \mathrm{~nm}$ wavelength was monitored with the PDA for $17 \beta$-estradiol separations. $17 \beta$-estradiol was also able to be observed at $225 \mathrm{~nm}$. When multiple steroids were separated, 200nm wavelength was monitored with the PDA for 17 $\beta$-estradiol, $17 \alpha-$ ethynyl estradiol, and estrone. Testosterone was monitored at $254 \mathrm{~nm}$. 


\subsection{Results and Discussion}

\subsubsection{Accounting for Nonspecific Binding}

It was observed in the blank experiment in which $17 \beta$-estradiol was incubated with beads but without aptamer that nonspecific binding occurs, and 17 $\beta$-estradiol was recovered after heating in the stacking buffer. In order to reduce the nonspecific binding, $10 \mathrm{mM}$ deoxyribonucleotide triphosphates were incubated with the beads.

Although nonspecific binding of estradiol is substantially reduced when the beads are blocked with deoxyribonucleotide triphosphates, it does occur. The secondary structure of the 76 base aptamer changes when co-incubated with a 24 base 5 ' reverse complement. When incubated with $95 \mu \mathrm{M}$ estradiol, the biotinylated aptamer-reverse complement complex more effectively reduced nonspecifically bound estradiol as compared to a biotinylated 18 base dT oligo ( $0.20 \pm 0.03$ vs. $0.29 \pm 0.02 \mu \mathrm{M})$. Based on this finding, the degree of nonspecific binding was determined by incubating five different concentrations of estradiol ranging from 30 to $95 \mu \mathrm{M}$ with the aptamer, the magnetic beads, and the 5' 24-base reverse complement of the aptamer. The value of nonspecific binding (NS) was estimated from the average slope of two determinations (0.0019 [estradiol recovered]/[estradiol total]). 


\subsubsection{Steroid Separations with Sample Stacking}

An electropherogram obtained with UV-visible absorbance detection at $200 \mathrm{~nm}$ is shown in Figure 3-4. The peak area of the DNA aptamer is substantially larger than steroids because of the higher concentration and different extinction coefficient. The traces shown in the inset of Figure 3-4 reveal the peaks obtained with steroids on an expanded y-axis. 


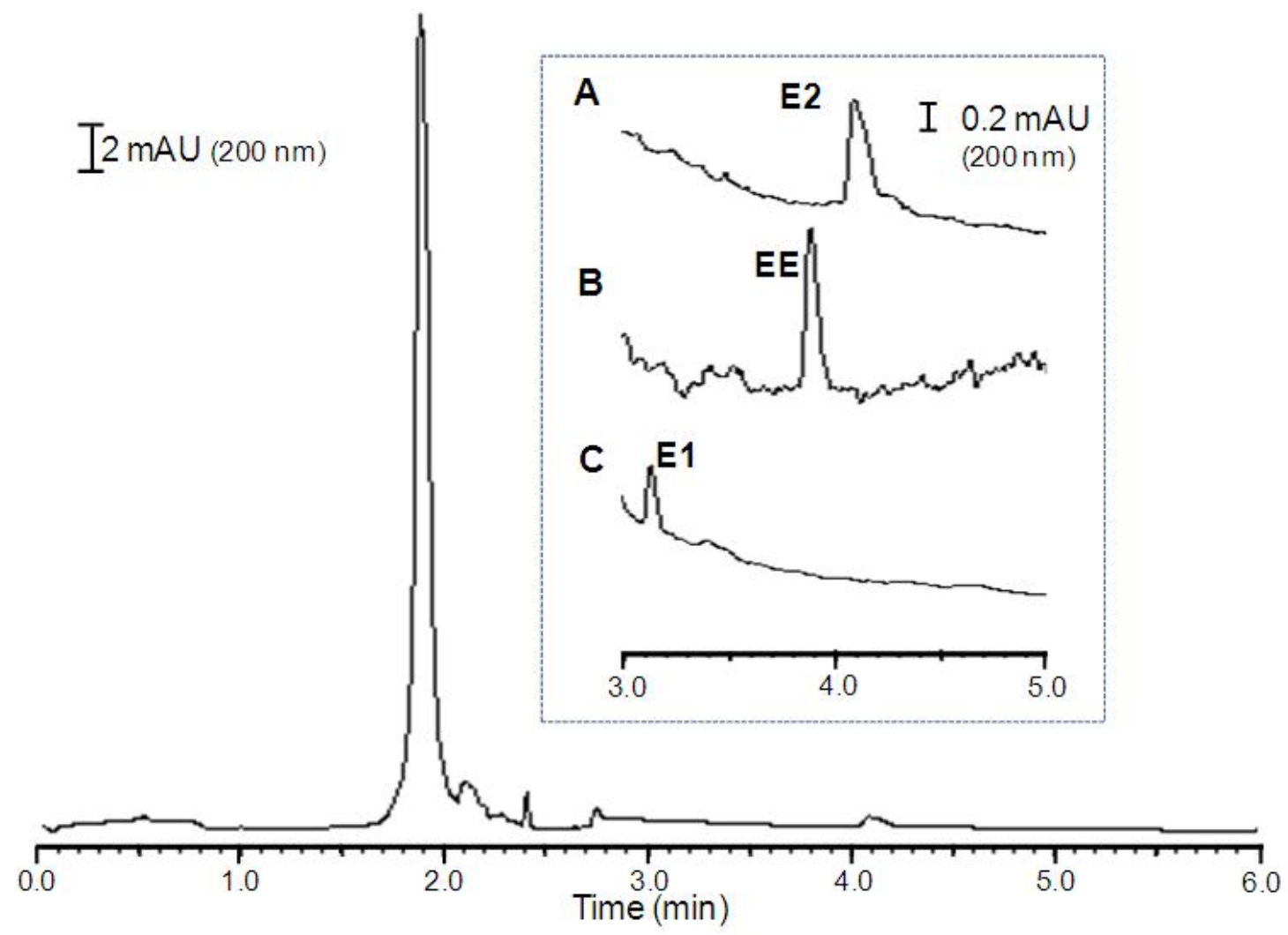

Figure 3-4: Electrophoretic separations following binding experiments. The inset shows a typical recovery of bound $17 \beta$-estradiol (E2) released from $2.2 \mu \mathrm{M}$ DNA aptamer (trace A). Traces B and C demonstrate the affinity experiments with $17 \alpha$-ethynyl estradiol (EE) and estrone (E1). Samples were injected at $-10 \mathrm{kV}$ for $60 \mathrm{~s}$ and separated at $-16 \mathrm{kV}$ using a $25 \mu \mathrm{m}$ i.d. capillary with a total and effective length of $30 \mathrm{~cm}$ and $10.2 \mathrm{~cm}$, respectively. 


\subsubsection{Quantification with Standard Addition}

Slight variability in the salt concentration in each sample affected the stacking efficiency and ultimately the quantification using external standards. The variability in salt concentration emanates from the flushing protocol. A small volume of solution remains on the beads and is unable to be collected by the pipette during flushes.

Increasing the number of repetitive flushes and the flushing volume addresses this issue, but extended flushing protocol could prematurely release and expel the bound estradiol, which would bias the measurement of dissociation constant. Thus, the estradiol in the sample was quantified using the method of standard addition for each measurement of bound estradiol. Samples were repetitively spiked to increase the estradiol concentration by either 0.10 or $0.15 \mu \mathrm{M}$ with each addition of standard. 


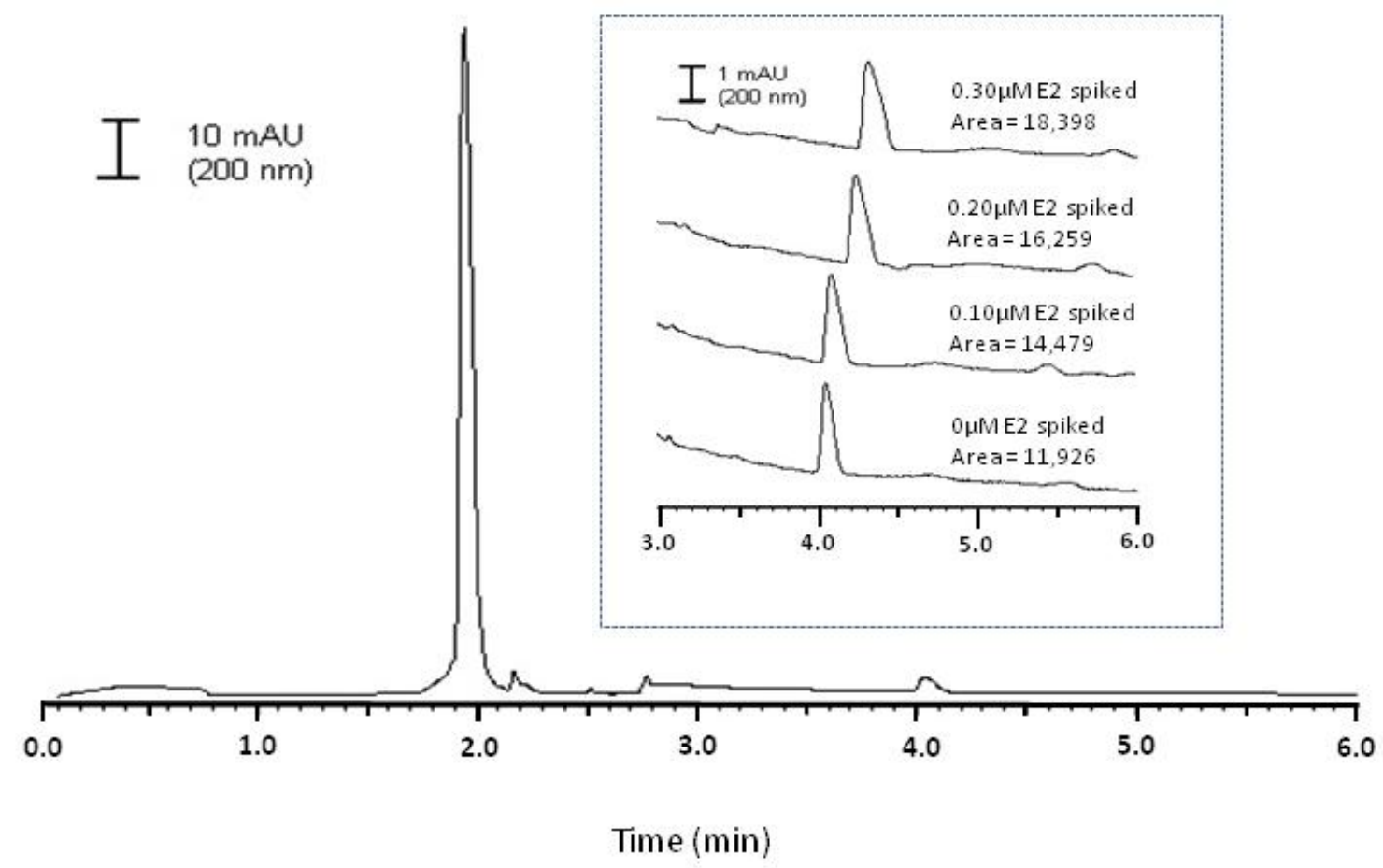

Figure 3-5: The electrophoretic separations following a single standard addition determination. The inset shows the traces of bound $17 \beta$-estradiol (E2). Samples were injected at $-10 \mathrm{kV}$ for 60 seconds and separated at $-16 \mathrm{kV}$ using a $25 \mu \mathrm{m}$ inner diameter capillary with a total and effective length of $30 \mathrm{~cm}$ and $10.2 \mathrm{~cm}$, respectively. 


\subsubsection{Determination of $K_{d}$ by Nonlinear Regression with Nonspecific Binding and Variations in $\mathbf{B}_{\max }$}

The $\mathrm{K}_{\mathrm{d}}$ is traditionally determined from Equation 2.8 as discussed in Chapter 1. However, there are practical limitations that make Equation 2.8 invalid. The first limitation encountered is the variability in aptamer concentration which causes $\left[\mathrm{R}_{\text {Total }}\right]$ to no longer be a constant. The second is nonspecific binding of $17 \beta$-estradiol which is not accounted for in Equation 2.8. These limitations require a workaround in order to account for nonspecific binding and the variability for [RL Bound $] /\left[\mathrm{R}_{\text {Total }}\right]$; Equation 2.8 can be rewritten as Equation 3.1.

Inconsistencies in $\left[\mathrm{R}_{\text {Total }}\right]$ can be caused by inconsistencies in sample preparations, which cause the variability in $\left[R L_{\text {Bound }}\right] /\left[R_{\text {Total }}\right]$. In the case of bead bound aptamer binding for estradiol, the amount of beads in each sample can be inconsistent. Therefore, $\left[\mathrm{R}_{\text {Total }}\right]$ is no longer a constant as in conventional calculating of $\mathrm{K}_{\mathrm{d}}$ from experimental results.

Equation 2.8

$$
\left[\mathrm{L}_{\text {Free }}\right] /\left(\mathrm{K}_{\mathrm{d}}+\left[\mathrm{L}_{\text {Free }}\right]\right)=\left(\left[\mathrm{RL}_{\text {Bound }}\right] /\left[\mathrm{R}_{\text {Total }}\right]\right)
$$

Rearrange both sides of Equation 2.8 by multiplying [ $\left.\mathrm{R}_{\text {Total }}\right]$ to get Equation 2.9. Equation 2.9

$$
\left(\left[\mathrm{R}_{\text {Total }}\right] \times\left[\mathrm{L}_{\text {Free }}\right]\right) /\left(\mathrm{K}_{\mathrm{d}}+\left[\mathrm{L}_{\text {Free }}\right]\right)=\left[\mathrm{RL}_{\text {Bound }}\right]
$$


$\mathrm{B}_{\max }$ is the maximum possible binding which in the case of one-to-one binding is equal to [ $\left.\mathrm{R}_{\text {Total }}\right]$ therefore Equation 2.9and be written as Equation 2.10

\section{Equation 2.10}

$$
\left(\mathrm{B}_{\max } \mathrm{x}\left[\mathrm{L}_{\text {Free }}\right]\right) /\left(\mathrm{K}_{\mathrm{d}}+\left[\mathrm{L}_{\text {Free }}\right]\right)=\left[\mathrm{RL}_{\text {Bound }}\right]
$$

Nonspecific binding must be accounted for in order to accurately calculate $\mathrm{K}_{\mathrm{d}}$. The plot of [ $\left.\mathrm{L}_{\text {Free }}\right]$ versus the concentration of observed ligand nonspecific binding yields the linear response which can be fit to Equation 2.11.

\section{Equation 2.11}

$$
\begin{aligned}
& \mathrm{NSB}=\mathrm{NS} \times\left[\mathrm{L}_{\text {Free }}\right] \\
& \text { Concentration of nonspecific binding = NSB }
\end{aligned}
$$

$$
\text { Slope of line }=\text { NS }
$$

In the case of bead bound aptamer binding for estradiol, the total observed binding estradiol is equal to the aptamer bound estradiol and the nonspecifically bound estradiol.

\section{Equation 2.12}

Concentration of observed bound estradiol $=\left[R L_{\text {Bound }}\right]+$ NSB . Equation 2.13 is derived from Equation 2.12 by substituting [RL $L_{\text {Bound }}$ from Equation 2.10 and NSB from Equation 2.11. 


\section{Equation 2.13}

Concentration of observed bound estradiol $=\left(B_{\max } x\left[L_{\text {Free }}\right]\right) /\left(K_{d}+\left[L_{\text {Free }}\right]\right)+N S x\left[L_{\text {Free }}\right]$ Equation 2.13 enables $K_{d}$ to be solved from a plot of [ $L_{\text {Free }}$ ] versus the concentration of observed bound estradiol.

Equation 3.1 (for nonlinear regression with nonspecific binding) $\mathbf{Y}=\left(\left(B_{\max } \mathbf{X}\right) /\left(K_{d}+X\right)\right)+N S \times X$

Where $\mathrm{Y}=$ concentration of observed bound estradiol

$$
\begin{aligned}
& \mathrm{B}_{\mathrm{max}}=\left[\mathrm{R}_{\text {Total }}\right]=\text { concentration of bead bound and properly folded aptamer } \\
& \mathrm{X}=\left[\mathrm{L}_{\text {Free }}\right]=\text { initial concentration of estradiol added to the sample }
\end{aligned}
$$

To determine the dissociation constant, the aptamer must be incubated with different amounts of estradiol, and the concentrations of aptamer as well as bound and free estradiol must be known for the calculation. Five different solutions of estradiol ranging from 30 to $95 \mu \mathrm{M}(30,48,65,83,95 \mu \mathrm{M})$ were incubated with DNA. The bound concentration was measured by sample stacking and capillary electrophoresis. The experiments are designed to utilize the same amount of DNA for each determination, but this varies with aliquoting and processing of the beads. The concentration of DNA recovered from the incubation was determined with a Thermo Scientific NanoDrop 1000 using a stacking buffer, spiked with the appropriate concentration of steroid as the measurement blank. The DNA recovered from each vial was normalized by dividing the concentration in a single set by the lowest concentration of DNA within the set. The bound estradiol was then divided by this factor. The normalized estradiol bound to DNA 
was plotted versus the concentration of free estradiol used for the incubation. The nature of the aptamer selection process generally results in 1:1 binding. The data were fit with GraphPad Prism version 4 using a one-site binding model described by the Equation 3.1. Nonlinear regression analysis yielded a dissociation constant of $K_{d}=70 \pm 10 \mu \mathrm{M}$ and a $\mathrm{B}_{\max }=0.42 \pm 0.03 \mu \mathrm{M}$ with an $\mathrm{R}^{2}$ of 0.998 for a single binding curve. The study was repeated, and the results were statistically similar $\left(\mathrm{K}_{\mathrm{d}}=80 \pm 40 \mu \mathrm{M}\right.$ and a $\mathrm{B}_{\max }=0.4 \pm$ $0.1 \mu \mathrm{M}$ with an $\mathrm{R}^{2}$ of 0.973$)$. 


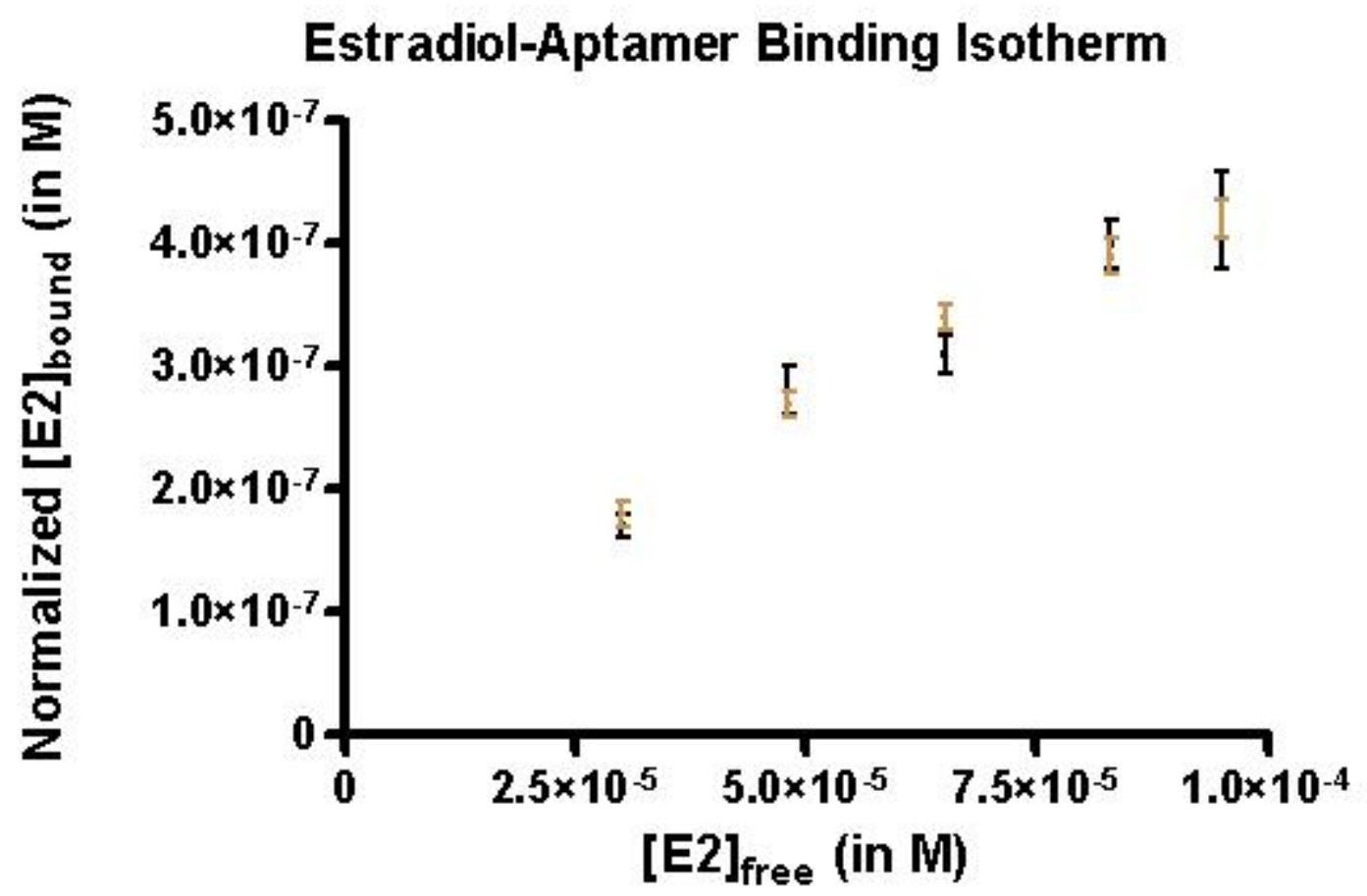

Figure 3-6: Two determinations of binding affinity of DNA aptamer and steroids. Following incubation, bound estradiol and DNA remained on the beads. During the incubation the DNA was immobilized via a streptavidin-biotin. The streptavidin-biotin interaction was destroyed by heating the beads in the stacking buffer, and the actual amount of DNA present during incubation was measured. This additional step corrects for variance associated with aliquoting the beads and with the biotin-DNA immobilization step. As the amount of DNA available for incubation varies for each estradiol determination (see Table 3-1), the ratio of bound estradiol to total DNA is plotted on the y-axis. The Equation 3.1 is used to fit nonlinear data where $\mathrm{Y}$ is the concentration of bound $17 \beta$-estradiol normalized and $\mathrm{X}$ is the concentration of free $17 \beta$ estradiol. The fit returns the $\mathrm{K}_{\mathrm{d}}$. 


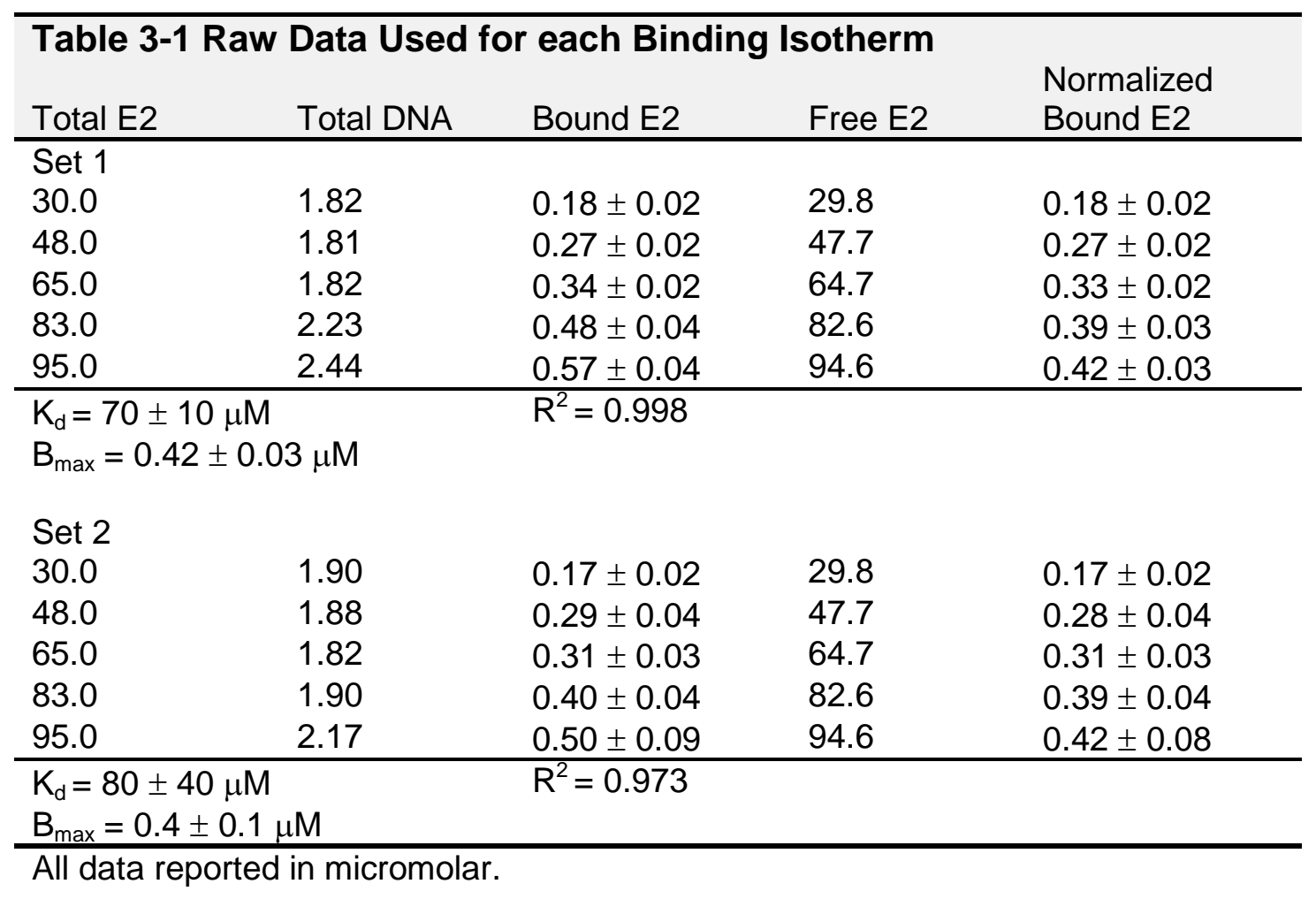


The dissociation constant of this biotinylated 76 base aptamer with estradiol was originally reported as $0.13 \mu \mathrm{M}[7]$. The 76 base sequence was also amino terminated, so that it could be covalently linked to isothiocyanate modified glass beads[9]. Differences in the measured dissociation constant may be due to the different linkages used for surface immobilization. CE measurements of binding affinity are useful because changes in the binding environment, for example loss of aptamer tertiary structure, affect the dissociation constant.

\subsubsection{Binding Affinity of Aptamer with Other Steroids}

The binding affinity of the aptamer was further determined with estrone and testosterone. Each of these steroids as well as $17 \beta$-estradiol was incubated at a concentration of $30 \mu \mathrm{M}$ (1.2 nanomoles) in $10 \mu \mathrm{M}$ ( 0.40 nanomoles) DNA in $40 \mu \mathrm{L}$ of deoxyribonucleotide triphosphate blocked beads $(4 \mathrm{mg} / \mathrm{mL}$ ) reconstituted in binding buffer. Steroids were recovered from the aptamer-immobilized beads at concentrations of $0.14 \pm 0.02 \mu \mathrm{M}$ (5.6 \pm 0.8 picomoles) for $17 \beta$-estradiol, $0.38 \pm 0.02 \mu \mathrm{M}(15 \pm 1$ picomoles) for estrone, and $0.25 \pm 0.03 \mu \mathrm{M}$ (10. \pm 1 picomoles) for testosterone. Blank incubations were performed for each steroid in which the beads were blocked with deoxyribonucleotide triphosphates, but no DNA was immobilized on the bead surface. Steroid was detected in the blanks incubated with $17 \beta$-estradiol $(0.06 \pm 0.02 \mu \mathrm{M})$ and estrone $(0.12 \pm 0.02 \mu \mathrm{M})$. These results demonstrate the binding capabilities of this aptamer sequence for other steroidal compounds. 


\subsection{Conclusions and Future Directions}

The dissociation constant for the immobilized DNA aptamer with $17 \beta$-estradiol was successfully measured using bead-binding experiments. The method demonstrates the use of capillary electrophoresis with secondary equilibria and $\mathrm{pH}$-mediated samplestacking as a rapid method to screening for aptamer affinity and to measure the dissociation constant. The utility of the method was demonstrated with successful separation of multiple steroids and their affinity for the immobilized DNA aptamer. The method was also able to successfully manipulate the folding and unfolding of the aptamer to bind and then release the steroids, thus enabling more specific selection.

Future experiments will be conducted to continue screening the aptamer for steroid affinity and to measure the dissociation constants of different steroid ligands with the aptamer. Also, the aptamer will be utilized to study $17 \beta$-estradiol in fish blood sample from future exposure studies. The aptamer will select the steroids which have affinity from the blood extract. Furthermore, CE separation is used to quantify the bound steroids that are released from the aptamer. From the bound steroid concentrations, the concentrations in the blood can be determined through knowing the dissociation constants for the steroids being observed. 


\subsection{Bibliography}

[1] Langan, T. J., Nyakubaya, V. T., Casto1, L. D., Dolan, T. D., et al., Electrophoresis Accepted October 23, 2011.

[2] Amundsen, L. K., Sirén, H., Electrophoresis 2007, 28, 99-113.

[3] Ye, L., Yu, Y., Mosbach, K., Analyst 2001, 126.

[4] Rachkov, A. E., Cheong, S.-H., El’skaya, A. V., Yano, K., Karube, I., Polymers for Advanced Technologies 1998, 9, 511-519.

[5] You, K., Lee, S., Im, A., Lee, S., Biotechnology and Bioprocess Engineering, The Korean Society for Biotechnology and Bioengineering 2003, pp. 64-75.

[6] Tuerk, C., Gold, L., Science 1990, 249, 505-510.

[7] Kim, Y. S., Jung, H. S., Matsuura, T., Lee, H. Y., et al., Biosensors and Bioelectronics 2007, 22, 2525-2531.

[8] Olowu, R. A., Ndangili, P. M., Baleg, A. A., Ikpo, C. O., et al., International Journal of Electrochemical Science 2011, 6, 1686-1708.

[9] Dong Huy, G., Jin, N., Yin, B.-C., Ye, B.-C., Bioprocess and Biosystems

Engineering, Springer Berlin / Heidelberg 2011, pp. 189-195.

[10] Olowu, R. A., Arotiba, O., Mailu, S. N., Waryo, T. T., et al., Sensors 2010, 10, 9872-9890.

[11] Giovannoli, C., Baggiani, C., Anfossi, L., Giraudi, G., Electrophoresis 2008, 29, 3349-3365.

[12] Bykova, L., Holland, L. A., Electrophoresis 2008, 29, 3794-3800. 
[13] Bykova, L., Archer-Hartmann, S. A., Holland, L. A., Iwanowicz, L. R., Blazer, V. S., Environmental Toxicology and Chemistry 2010, 29, 1950-1956.

[14] Ji, A. J., Nunez, M. F., Machacek, D., Ferguson, J. E., et al., J. Chromatogr. B, Biomed. Appl. 1995, 669, 15-26.

[15] Munro, N. J., Palmer, J., Stalcup, A. M., Landers, J. P., J. Chromatogr., B: Biomed. Appl. 1999, 731, 369-381.

[16] Chan, K. C., Muschik, G. M., Issaq, H. J., Siiteri, P. K., Journal of Chromatography A 1995, 690, 149-154.

[17] Deng, Y., Zhou, J., D. Perkins, M., M. Lunte, S., Analytical Communications 1997, 34, 129-131.

[18] Katayama, M., Matsuda, Y., Shimokawa, K.-i., Kaneko, S., Biomedical Chromatography 2003, 17, 263-267.

[19] Regan, F., Moran, A., Fogarty, B., Dempsey, E., Journal of Chromatography A 2003, 1014, 141-152.

[20] Du, B., Song, S., Shi, X., Zhang, Z., Journal of Analytical Chemistry 2009, pp. 5964.

[21] Bani-Yaseen, A., Kawaguchi, T., Price, A., Culbertson, C., Jankowiak, R., Analytical and Bioanalytical Chemistry, Springer Berlin / Heidelberg 2011, pp. 519-524.

[22] Flor, S., Lucangioli, S., Contin, M., Tripodi, V., Electrophoresis 2010, 31, 33053313.

[23] Holmberg, A., Blomstergren, A., Nord, O., Lukacs, M., et al., Electrophoresis 2005, 26, 501-510. 


\section{Curriculum Vitae}


Ted Langan

Email: ted.langan@gmail.com

\section{$\underline{\text { Education }}$}

\section{Ph.D. in Chemistry Specialization: Analytical Chemistry}

2005- 2012 West Virginia University

Overall GPA: 3.87

Area(s) of Interest: analytical chemistry, separations, capillary electrophoresis, mass spectrometry

BS in Chemistry and Mathematics minor

2001-2005 Frostburg State University

Overall GPA: 3.829

Chemistry GPA: 4.0

\section{Techniques and Skills}

Separation techniques: capillary electrophoresis (free zone, affinity, MEKC, phospholipid enhanced), liquid chromatography (reversed phase, normal phase, anion exchange), detection (UV-Visible, laser induced fluorescence)

Mass spectrometry: Ion sources (Electrospray/nanospray), CE/MS coupling (Coaxial sheath flow interface, microfluidic chip, sheathless fracture interface), and mass analyzers (Thermo Scientific LCQ DECA ion trap, SSQ -7000 single quadrupole, TSQ7000 triple quadrupole

Fabrication techniques: Photolithograph and HF wet etching for production of microfluidic chips

Software: 32Karat V5.0 and V7.0 (Beckman Coulter), IGOR Pro V4.0 (National Instruments), Graphpad Prism V4.0 (Graphpad Software), ImageJ V1.41 (NIH), Microsoft Office Applications, Windows, Linux, Xcaliber, LCQ tune v.1.1 (Thermo Scientific), Maxwell 2D software, LabVIEW

Instrument used, maintenance, and repaired: Beckman P/ACE MDQ, Thermo LCQ DECA, SSQ -7000, TSQ-7000, Spellman 1000R, Labsmith HV448 high voltage sequencer, custom HV sources, custom CE systems, $18 \mathrm{M} \Omega$ water system, Nikon TE300 inverted fluorescence microscope with an ORCA-R2 air-cooled CCD camera, Aphastep surface profiler

Instructional instruments: ICP, HPLC, GC, UV-visible spectrometer, fluorescence spectrometer 


\section{Teaching Experience}

-Attended WVU Summer Institute 2011

-Assistant director with SURE/REU Summer 2011

-Teaching assistant 2005-08

-Guest/substitute lecturer for Instrumental Analysis for Dr. Holland 2008-2011

-"Supervising Teaching Assistant" experiment implementation and taught Instrumental Lab- class \#313- Fall 2011

-Conducted weekly group tutoring as teaching assistant for Dr. Babb for General Chemistry 2 class \#116 - Fall 2011

-"Supervising Teaching Assistant" Chemistry \#112- Spring 2012

\section{Accepted Publications}

Ted J. Langan, Lisa A. Holland "Capillary electrophoresis coupled to electrospray mass spectrometry through a coaxial sheath flow interface and semi-permanent phospholipid coating for the determination of oligosaccharides labeled with 1-aminopyrene-3,6,8trisulfonic acid” Submitted Aug. 2011 Electrophoresis

Ted J. Langan , Vincent T. Nyakubaya , Laura D. Casto , Tiffany D. Dolan, Stephanie A. Archer-Hartmann, Letha J. Sooter, and Lisa A. Holland "Assessment of AptamerSteroid Binding Using Stacking Enhanced Capillary Electrophoresis” Submitted Aug. 2011 Electrophoresis

R. Luo, T.J. Langan, L.A. Holland, "Distance Learning Module III: The Separation of Neutral Compounds Using Micelle Electrokinetic Capillary Chromatography”, December 2006, Analytical Sciences Digital Library

R. Luo, T.J. Langan, L.A. Holland, "Distance Learning Module IV: Separation of Anionic Compounds Using Micelle Electrokinetic Capillary Chromatography", December 2006 Analytical Sciences Digital Library 


\section{$\underline{\text { Presentations }}$}

Ted Langan, Lisa Holland, “Design of Fracture Decoupled Capillary ElectrophoresisMass Spectrometry”, West Virginia University, Pittsburgh Conference in Chicago, February 28, 2007

Ted Langan, Lisa Holland, “Capillary Electrophoresis-Sheathless Electrospray Mass Spectrometry Using a Fracture Decoupler and Pulled Tip Capillary”, West Virginia University, Pittsburgh Conference in New Orleans, March 5, 2008

Ted Langan, Lisa Holland, "Phospholipids Enhanced Capillary Electrophoresis with Electrospray Mass Spectrometry”, West Virginia University, Pittsburgh Conference in Chicago, 2009

Ted Langan, Lisa Holland, "Enhancing Capillary Electrophoresis with Phospholipids and Coupling with Electrospray Mass Spectrometry”, West Virginia University, Pittsburgh Conference in Chicago, 2010

\section{$\underline{\text { Awards }}$}

Organic Chemistry Polymer Award 2003

2005 Chemistry Department Award from Frostburg State University

Magna Cum Laude at Frostburg State University in 2005

\section{$\underline{\text { Activities }}$}

Member of the American Chemical Society (ACS), Member of KME (Mathematics Honor Society at FSU), President of the Student Affiliates of ACS (FSU 2004-2005), Vice President of the Student Affiliates of ACS (FSU Spring 2004), Vice President of KME (FSU 2004-2005) Member of PLU:(Chemistry Honorary WVU) 